\title{
Constructal Theory: From Engineering to Physics, and How Flow Systems Develop Shape and Structure
}

\author{
A. Heitor Reis \\ Physics Department and Évora \\ Geophysics Center, \\ University of Évora, \\ R. Romão Ramalho, 59, \\ 7000-671 Évora, Portugal
}

Constructal theory and its applications to various fields ranging from engineering to natural living and inanimate systems, and to social organization and economics, are reviewed in this paper. The constructal law states that if a system has freedom to morph it develops in time the flow architecture that provides easier access to the currents that flow through it. It is shown how constructal theory provides a unifying picture for the development of flow architectures in systems with internal flows (e.g., mass, heat, electricity, goods, and people). Early and recent works on constructal theory by various authors covering the fields of heat and mass transfer in engineered systems, inanimate flow structures (river basins, global circulations) living structures, social organization, and economics are reviewed. The relation between the constructal law and the thermodynamic optimization method of entropy generation minimization is outlined. The constructal law is a self-standing principle, which is distinct from the Second Law of Thermodynamics. The place of the constructal law among other fundamental principles, such as the Second Law, the principle of least action and the principles of symmetry and invariance is also presented. The review ends with the epistemological and philosophical implications of the constructal law. [DOI: 10.1115/1.2204075]

\section{Introduction}

Constructal theory and the constructal law are terms that we see more and more in the current scientific literature. The reason is that increasing numbers of people use the constructal paradigm to optimize the performance of thermofluid flow systems by generating geometry and flow structure, and to explain natural selforganization and self-optimization. Constructal theory is a principle-based method of constructing machines, which attain optimally their objective. Constructal theory offers a different look at corals, birds, atmospheric flow and, of course, at machines in general.

There is an old history of trying to explain the forms of nature-why leaf has nerves, why a flower has petals. This history is as old as people have existed. Geometry has focused on explaining form, and has contributed to much of the knowledge inherited from antiquity.

For the first time, engineers have entered an arena where until now the discussion was between mathematicians, physicists, biologists, and zoologists. The engineers enter with a point of view that is very original, and which may enlighten the questions with which others have struggled until now.

Adrian Bejan is at the origin of the constructal paradigm, which had its start in 1996. In his books [1,2] he tells that the idea came to him when he was trying to solve the problem of minimizing the thermal resistance between an entire heat generating volume and one point. As the optimal solution, he found "a tree network in which every single feature was a result, not an assumption," and drew the conclusion that every natural tree structure is also the result of optimization of performance of volume-point flow. As natural tree structures are everywhere, and such structures are not deducible from a known law, he speculated that the optimization of configuration in time must be a new principle and called it the Constructal Law. He stated this law as follows: For a finite-size system to persist in time (to live), it must evolve in such a way that

Transmitted by Assoc. Editor E. Dowell. it provides easier access to the imposed (global) currents that flow through it.

A new statement deserves recognition as a principle only if it provides a conceptual framework for predicting form and evolution of form and for modelling natural or engineered systems. Bejan has not only formulated the constructal principle but also developed a method for applying it to practical situations. The constructal method (Bejan [1-6]) Bejan and Tondeur [7]) is about the generation of flow architecture in general (e.g., duct cross sections, spacings, tree networks). For example, the generation of tree-shaped architecture proceeds from small parts to larger assemblies. The optimal structure is constructed by optimizing volume shape at every length scale, in a hierarchical sequence that begins with the smallest building block, and proceeds towards larger building blocks (which are called "constructs").

A basic outcome of constructal theory is that system shape and internal flow architecture do not develop by chance, but result from the permanent struggle for better performance and therefore must evolve in time. Natural systems that display an enormous variety of shapes are far from being perfect from the geometric point of view. Geometric perfection means symmetry (e.g., the sphere has the highest possible geometric symmetry); but in the physical (real) world the higher the internal symmetry the closer to equilibrium, to no flow, and death. We know that translational symmetry (invariance) with respect to temperature, pressure and chemical potential means thermal, mechanical, and chemical equilibrium, respectively, while translational or angular invariance of the Lagrangian means conservation of linear and angular momentum, respectively (Noether's theorem). Nevertheless, it is almost impossible to find the perfect geometric form in animate systems because they are far from equilibrium; they are alive, and imperfection (physical and geometrical asymmetry) is the sign that they are alive. Yet, they work "best" because they minimize and balance together the resistances faced by the various internal and external streams under the existing global constraints.

Nonequilibrium means flow asymmetry and imperfection. Imperfection is either geometric (e.g., quasicylindrical channels, 
quasispherical alveolus, quasicircular stoma, etc.) or physical (unequal distribution of stresses, temperature, pressure, etc.). Therefore, internal imperfections are optimally distributed throughout the system (Bejan [1,2]). The actual form of natural systems that were free to morph in the past is the result of optimal distribution of imperfection, while engineered systems approach the same goal and structure as they tend to optimal performance.

The constructal law is self-standing and distinct from the Second Law (Bejan $[1,8,9]$ ). Unlike the Second Law that accounts for the one-way nature of flows (i.e., irreversibility), the constructal law is about the generation of flow configuration, structure, and geometry. Its field of application is that of dissipative processes (flows that overcome resistances), entropy generation, and nonequilibrium thermodynamics. In recent papers, Bejan and Lorente $[8,9]$ outlined the analogy between the formalism of equilibrium thermodynamics and that of constructal theory (see Sec. 6). In what follows, we outline the main features of constructal theory, and present an overview of recent developments and applications to various fields.

\section{Constructal Method}

Constructal theory holds that every flow system exists with purpose (or objective, function). In nature, flows occur over a wide range of scales with the purpose of reducing the existing gradients (temperature, pressure, etc.). In engineered and living structures heat and mass flows occur for the same reason, and by dissipating minimum exergy they reduce the food or fuel requirement, and make all such systems (animals, and "man + machine" species) more "fit," i.e., better survivors. They "flow" better and better, internally and over the surface of the earth.

The purpose of heat engines is to extract maximum useful work from heat currents that flow between systems at different temperatures. Other machines work similarly; i.e., with purpose, e.g., by collecting or distributing streams, or for enhancing heat or mass transfer. Performance is a measure of the degree to which each system realizes its purpose. The design of engineered systems evolves in time toward configurations that offer better performance, i.e., better achievement of their purpose.

The system purpose is global. It is present along with fixed global constraints, which may include the space allocated to the system, available material and components, allowable temperature, pressure or stress ranges, etc. The system designer brings together all components, and optimizes the arrangement in order to reach maximum performance. In this way he "constructs" the optimal flow architecture. Therefore, the flow architecture (shape, structure) is deduced, not assumed in advance. Unlike optimizing procedures that rely on operational variables, constructal theory focuses on the construction of optimal flow architecture, internal and external.

Optimization makes sense only when purpose exists and the problem-solver has the freedom to morph the configuration in the search of the best solution within the framework of a set of constraints. The constraints may vary from allowable materials, material properties, area or volume allocated to the system, requirements to avoid hot-spots, or not to surpass maximal values of temperature, pressure, stresses, etc. Depending on the system's nature, optimization may focus on exergy analysis (e.g., Bejan $[10,11]$ ), entropy generation (e.g. Bejan $[12,13]$ ), thermoeconomics (e.g., Bejan et al.. [14]) or minimization of highest stress, temperature or pressure (e.g., Bejan [2,6], Bejan and Tondeur [7]).

The minimization of pressure peaks (Bejan $[1,2,6]$, Bejan and Errera [15]) is a good way to illustrate the constructal method. The problem may be formulated as follows:

"A fluid has to be drained from a finite-size volume or area at a definite flow-rate through a small patch located on its boundary. The flow is a volume-point or area-point. It is a special and very important type of flow, because it connects one point with an infinity of points. The volume is a nonhomogeneous porous medium composed of a material of low permeability $K$ and various

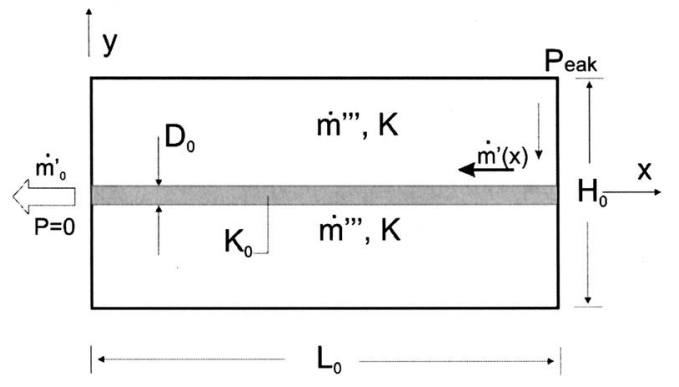

Fig. 1 Elemental volume: the central high-permeability channel collects flow from low permeability material

layers of higher permeabilities $\left(K_{0}, K_{1}, \ldots\right)$. The thicknesses $\left(D_{0}, D_{1}, \ldots\right)$ and lengths $\left(L_{0}, L_{1}, \ldots\right)$ of these layers are not specified. Darcy flow is assumed to exist throughout the volume considered. Determine the optimal arrangement of the layers through the given volume such that the highest pressure is minimized."

A first result is the use of the high permeability material where flow rates are highest. Conversely, low permeability material shall be used for low flow rates. Next, we choose an elemental volume of length $L_{0}$ and width $H_{0}$, filled with the low permeability $(K)$ isotropic porous medium (e.g., Fig. 1), and use higher permeability $\left(K_{0}\right)$ material to drain the fluid from it. The area $A_{0}=H_{0} L_{0}$ of the horizontal surface is fixed but the shape $H_{0} / L_{0}$ is not.

Because of symmetry and objective (optimization), the strip that collects fluid from the isotropic porous medium must be aligned with the $x$ axis. And, because the flow-rate $\dot{m}_{0}^{\prime}$ is fixed, to minimize the peak pressure means to minimize the global flow resistance. The peak pressure occurs in two corners (P, Fig. 1), and is given by

$$
P_{\text {peak }}=\dot{m}_{0}^{\prime} \nu\left(H_{0} / 8 K L_{0}+L_{0} / 2 K_{0} D_{0}\right)
$$

where $\mathrm{D}_{0}$ represents the thickness of the central strip. By minimizing the peak pressure with respect to the shape parameter $H_{0} / L_{0}$ we find that the optimum geometry is described by

$$
\begin{array}{cc}
\tilde{H}_{0}=2^{1 / 2}\left(\tilde{K}_{0} \phi_{0}\right)^{-1 / 4} & \tilde{L}_{0}=2^{-1 / 2}\left(\tilde{K}_{0} \phi_{0}\right)^{1 / 4} \\
H_{0} / L_{0}=2\left(\widetilde{K}_{0} \phi_{0}\right)^{-1 / 2} & \Delta \widetilde{P}_{0}=2^{-1}\left(\widetilde{K}_{0} \phi_{0}\right)^{-1 / 2}
\end{array}
$$

where $\phi_{0}=D_{0} / H_{0} \ll l, \quad \Delta \widetilde{P}_{0}=P_{\text {peak }}\left(\dot{m}_{0}^{\prime} A_{0} \nu / K\right)$, and the tilde $(\sim)$ indicates nondimensionalized variables based on $\left(A_{0}\right)^{1 / 2}$ and $K$ is length and permeability scales.

Equations (2) pinpoint the optimal geometry that matches minimum peak pressure and minimum resistance. The first of Eqs. (3) indicates another important result: the two terms on the right-hand side of Eq. (1) are equal; said another way, "the shape of the elemental volume is such that the pressure drop along the central strip is equal to the pressure drop along the isotropic porous medium ( $K$ layer)." This is the constructal law of equipartition of the resistances (Bejan [1,2], Bejan and Tondeur [7]). An analogous result for electric circuits was obtained by Lewins [16] who, based on the constructal theory, found an equipotential division between the competing regimes of low and high resistance currents.

Next, consider a larger volume (a "first construct") filled entirely with elemental volumes. This "first construct" is shown in Fig. 2. Once again, symmetry and objective dictate that the higher permeability strip that collects all the currents from the elemental volumes must be aligned with the horizontal axis of the first construct. The geometry of the first construct, namely the number $n_{1}$ of elemental volumes in the construct, is optimized by repeating the procedure used in the optimization of the elemental volume. $C_{i}=\widetilde{K}_{i} \phi_{i}$, the parameters defining the optimized first construct are (Bejan [1]) 


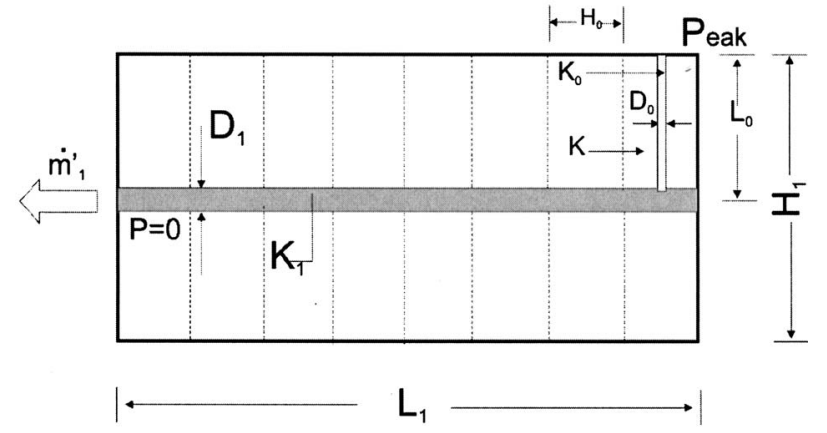

Fig. 2 First construct made of elemental volumes. A new channel of higher permeability collects flow from the elemental volumes.

$$
\begin{gathered}
\tilde{H}_{1}=2^{1 / 2}\left(C_{0}\right)^{1 / 4} \quad \tilde{L}_{1}=C_{0}^{-1 / 2} C_{1}^{1 / 2} \\
H_{1} / L_{1}=\left(2 C_{0} / C_{1}\right)^{1 / 2} \quad \Delta \widetilde{P}_{1}=\left(2 C_{0} / C_{1}\right)^{-1 / 2} \\
n_{1}=\left(2 C_{1}\right)^{1 / 2}
\end{gathered}
$$

Higher order constructs can be optimized in a similar way until the specified area is covered completely. What emerges is a twodimensional fluid tree in which optimization has been performed at every volume scale. The fluid tree is the optimal solution to two problems: the flow architecture that matched the lowest peak pressure, and the one that matched to lowest pressure averaged over the tree.

The constructal law can also be used in the same problem by basing the optimization on minimizing the pressure averaged at each scale of the fluid tree. Three-dimensional fluid trees may be optimized in an analogous manner (Bejan $[1,2,6])$. The same procedure applies to heat transfer trees (Bejan [1-3], Bejan and Tondeur [7], Bejan and Dan [17,18], Ledezma and Bejan [19]).

\section{Optimization as a Trade-Off Between Competing Trends}

There are two competing trends in the example of Sec. 2. Increasing the length $L_{0}$ of the central strip leads to a decrease in the resistance posed to flow in the $K$ layer, but it also increases the resistance along the central channel (cf. Eq. (1)). Optimization meant finding the best allocation of resistances, and therefore the geometry of the system that allows best flow access from the area to the outlet. The law of equipartition of pressure losses summarizes the result of optimization of such flow access.

The optimum balance between competing trends is at origin of "equilibrium" flow architectures in both engineered and natural systems, and is in the domain of constructal theory. Like the thermodynamic equilibrium states that result from the maximization of entropy (or the minimization of free energy) in nonflow systems in classical thermodynamics, equilibrium flow architectures spring out of the maximization of flow access (Bejan and Lorente $[8,9])$.

Consider the following example of optimization under competing trends. Air at temperature $T_{0}$ is made to flow at rate $\dot{m}$ through a set of equidistant heat generating boards of length $L$ and width $W$ (perpendicular to the plane of the figure) filling a space of height $H$ (Fig. 3). The board-to-board spacing $D$, is to be determined in order to maximize the rate $q$ at which heat is removed. As a local constraint, the temperature must not exceed a specified value, $T_{\max }$. Other assumptions are laminar flow, smooth board surfaces, and that the temperature along every board is close to $T_{\max }$.

Small board-to-board spacings permit a large number of boards $(n=H / D)$ to be installed and cooled. Although in this limit the

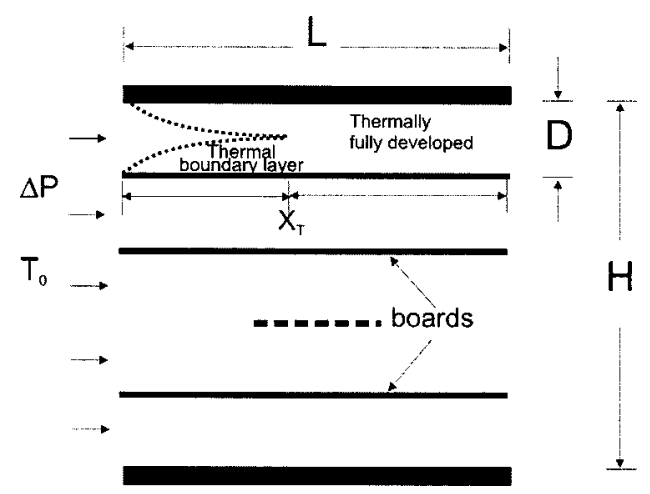

Fig. 3 The optimal spacing comes out of the trade-off between heat transfer surface and resistance to fluid flow. Board to board spacing is optimal when every fluid volume is used for the purpose of heat transfer.

contact heat transfer area is large, the resistance to fluid flow is also large. The optimal spacing $D_{\text {opt }}$ must come out of the balance between these two competing trends, fluid flow resistance against thermal resistance. For very small spacings (large $n$ ) the heat transfer rate is (Bejan [1]):

$$
q=\rho H W\left(D^{2} / 12 \mu\right)(\Delta P / L) c_{p}\left(T_{\max }-T_{0}\right)
$$

where $\rho, \mu$, and $c_{p}$ stand for density, viscosity, and specific heat, respectively. For large spacing (small $n$ ), each plate is coated by distinct boundary layers, and the heat transfer rate is given by [1]:

$$
q=1.21 k H W\left[\operatorname{Pr} L \Delta P /\left(\rho \nu^{2} D^{2}\right)\right]^{1 / 3}\left(T_{\max }-T_{0}\right)
$$

where $k, \nu$, and $P_{r}$ are thermal conductivity, kinematic viscosity, and Prandlt number, respectively.

Equation (7) shows that the heat transfer rate $q$ increases asymptotically with $D^{2}$ as $n$ becomes smaller (Eq. (7)), while when $n$ becomes larger it varies asymptotically as $D^{-2 / 3}$ (Eq. (8)). Therefore, the number of boards for which the heat transfer rate is maximum can be determined approximately by using the method of intersecting the asymptotes (Bejan [1,20,21], as shown in Fig. 4. The optimal spacing is given by

$$
D_{\text {opt }} / L \propto \mathrm{Be}^{-1 / 4}
$$

where $\mathrm{Be}=\left(\Delta P L^{2}\right) /(\mu \alpha)$ is what Bhattacharjee and Grosshandler [22] and Petrescu [23] called the Bejan number.

The spacing defined by Eq. (9) is not only the optimal solution to maximum heat transfer while keeping the temperature below $T_{\max }$, but also is the solution to the problem of packing maximum heat transfer rate in a fixed volume. The best elementary construct to this second problem is a heat transfer board whose length

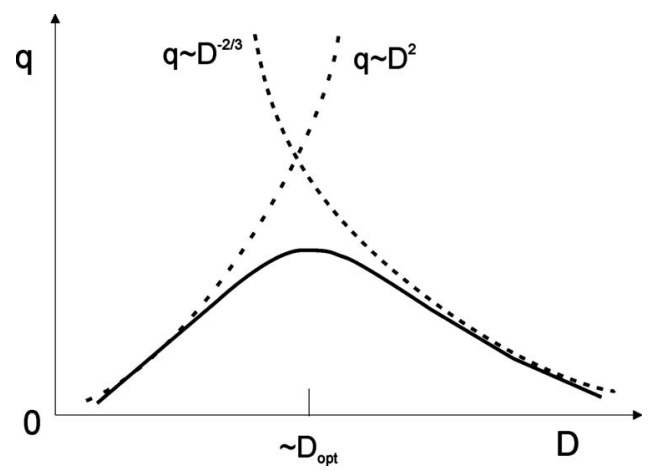

Fig. 4 The intersection of the asymptotes corresponding to the competing trends indicates the optimum spacing for maximum thermal conductance of a stack of parallel boards 


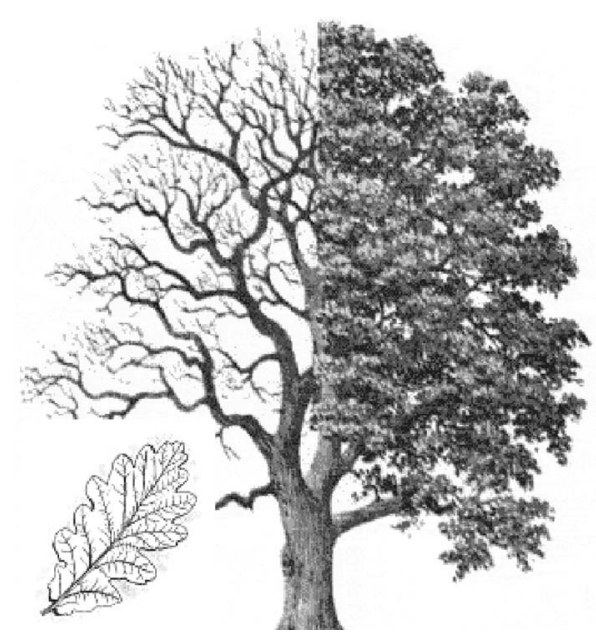

Fig. 5 Examples of point-to-volume flow architectures: tree and leaves

matches the entrance length $X_{T}$ (see Fig. 3). Maximum packing occurs when every packet of fluid is used for transferring heat. If $L<X_{T}$, the fluid in the core of the channel does not interacts thermally with the walls, and therefore does not participate in the global heat transfer enterprise. In the other extreme, $L>X_{T}$, the flow is fully developed, the fluid is saturated thermally and it overheats as it absorbs additional heat from the board walls.

The optimal spacing determined in this manner enables us to see the significance of the Bejan number. In steady conditions, the rate at which heat is transferred from the boards to the fluid, $\bar{h}\left(T_{\max }-T_{0}\right) W L$, must equal the rate of enthalpy increase $\rho v c_{p}\left(T_{\max }-T_{0}\right) D W$, where $v=\left[(\Delta P) D^{2}\right] /(12 \mu)$, which is removed by the cooling fluid that flows under the pressure difference $\Delta P$. Therefore, for $L_{\mathrm{opt}}=X_{T}$ this equality of scales reads

$$
\mathrm{Be}=12 \mathrm{Nu}_{D}\left(L_{\text {opt }} / D_{\text {opt }}\right)^{4}
$$

which matches Eq. (9). In Eq. (10), $\mathrm{Nu}_{D}=\bar{h} D / k=\left(\partial T^{*} / \partial z^{*}\right)$ is Nusselt number based on $D_{\text {opt }}$ (where $T^{*}=T /\left(T \max -T_{0}\right)$ and $z^{*}$ $\left.=z / D_{\text {opt }}\right)$, which is a constant of order 1 .

By analogy with Sec. 2, optimized convective heat trees can be constructed at every scale by assembling and optimizing constructs that have been optimized at the preceding scale (Bejan [1], Ledezma and Bejan [19]). Similarity exists between the forced convection results and the corresponding results for natural convection. The role played by Bejan number Be in the forced convection is played in natural convection be the Rayleigh number $\mathrm{Ra}$ (Petrescu [23]).

\section{The Ubiquitous Search for Flow Configuration: Fields of Application of Constructal Theory}

Flow architectures are ubiquitous in nature. From the planetary circulations to the smallest scales we can observe a panoply of motions that exhibit organized flow architectures: general atmospheric circulations, oceanic currents, eddies at the synoptic scale, river drainage basins, dendritic crystals, etc. Fluids circulate in all living structures, which exhibit special flow structures such as lungs, kidneys, arteries and veins in animals, and roots, stems, leaves in plants (Fig. 5).

Transportation networks where goods and people flow, have been developed for the purpose of maximum access-best performance in economics and for facilitating all human activities. Similarly, internal flow structures where energy, matter and information flow are at the heart of engineered systems.

Flow architectures in both living and engineered systems evolve toward better performance, and persist in time (they sur- vive) while the older disappear (Bejan $[1,24,25])$. This observation bridges the gap between the constructal law and the Darwinian view of living systems. Results of the application of constructal theory have been published in recent years for various natural and engineered systems. In the following, we briefly review some of the most important results of constructal theory.

4.1 Engineering. Optimization is a basic thought and activity in engineering. What the constructal law brought to the field is that flow structure is not assumed in advance to the optimization process, but is its consequence. The emergence of three-shaped networks as the result of optimization has been noticed by authors using other methods (e.g., Borrvall et al. [26], Nakayama [27], Brod [28]) These methods have the distinctive feature that allow the system "freedom to morph." In this way, they are like constructal theory, although constructal theory proclaims the general applicability of the principle.

Optimization of tree networks for volume-to-point and point-tovolume movement is a special field of application for constructal theory (see, for example Refs. [29-60]). The purpose of the optimization depends on the characteristics of the problem, for example, minimization of pumping power, maximization of hear exchange (thermal conductance, etc.) while constraints may include total volume or total surface, available material (ducts), the requirement not to exceed peak pressure or temperature, etc. Optimization of flow geometry proceeds hierarchically from small to large, from the elemental system (the smallest scale) to larger constructs (higher order scales).

Generally, the constructal law dictates rules for the optimized structure at every scale. The rules are derived, not assumed. Results show that these rules change from one scale level to the next, as the tree size and complexity increase. Complexity is optimized, and is a result of the optimization process. Optimized complexity must not be confused with maximized complexity.

A good example is the distribution of hot water to a growing number of users that are spread over an area. The optimization of such a flow tree may be pursued under several objectives, for example: (i) maximization of the temperature of the hot water received by the most disadvantaged user; (ii) minimization of the heat losses over the entire piping network or (iii) maximization of the hot water temperature averaged over all the users (Wechsatol et al. [51]). The constraints may range from the size and shape of the area to be served by the piping system to the amount of insulation and total volume occupied by the ducts. Strategies that have been proposed include the constructal sequence (Sec. 2) and the "one-by-one growth," where, at each step in time, one new user is added to an existing structure. Lorente et al. [45-47] found that several strategies lead to similar tree flows, and to comparable levels of global performance. One strategy is based on the observation that every duct has the lowest flow resistance when it has the shortest path possible on the area allocated to it. This method is important because it allows the optimization to be performed locally (Fig. 6). Comparison between the excess temperatures of the water received by end users shows that the constructal tree design was consistently superior to the string arrangement especially when the insulation was imperfect (Lorente et al. [45]).

The augmentation of heat transfer systems is an active field of application of constructal theory. Matos et al. [61,62] made a three-dimensional numerical and experimental geometric optimization study on the maximization of the total heat transfer rate between a bundle of finned tubes in a given volume and external flow, for staggered arrangements of circular and elliptic tubes. They defined global optima with respect to tube-to-tube spacing, eccentricity, and fin-to-fin spacing.

Kraus [63] used constructal theory for finding the optimum longitudinal fin of rectangular profile with tip heat loss. Bonjour et al. [58] optimized the design of dendritic fins for a coaxial twostream heat exchanger. They showed that depending on the size of the system the best configuration can be either a radial pattern or a tree of fins. 
(a)

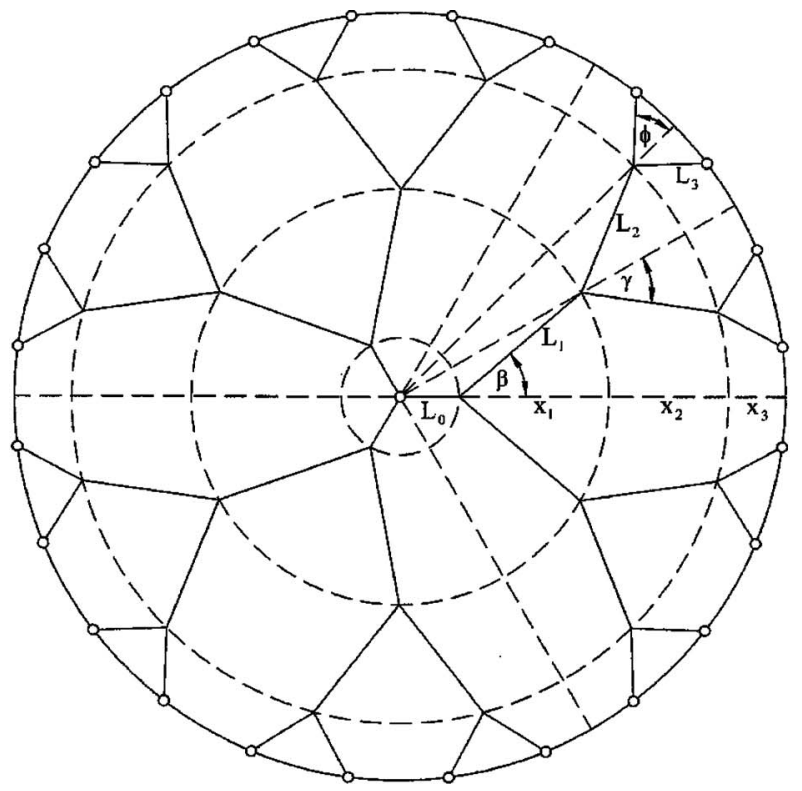

(b)

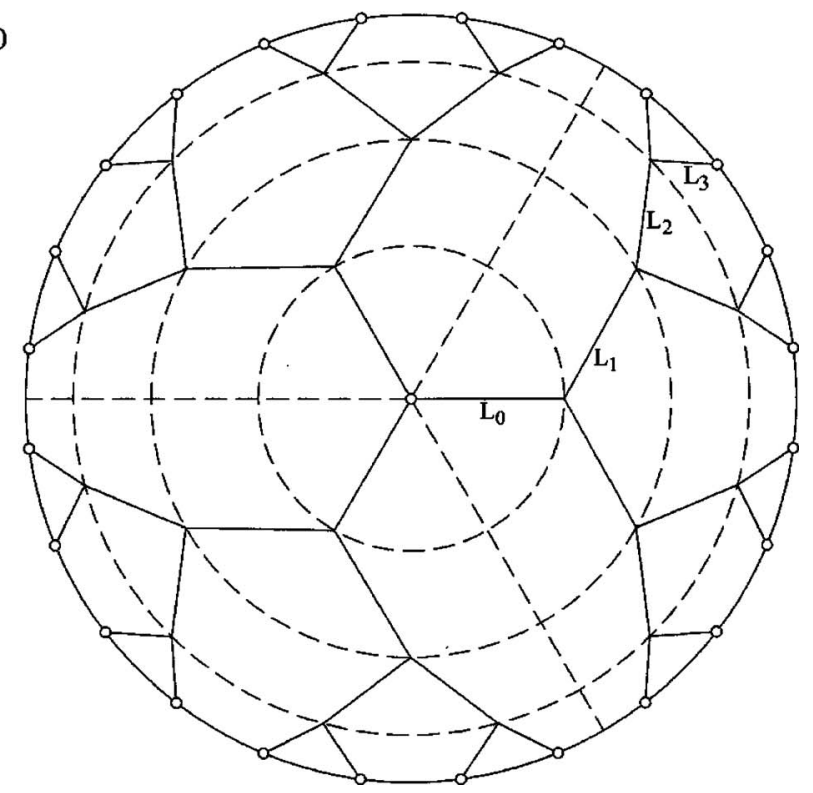

Fig. 6 (a) Global optimization of the duct tree, and (b) step by step locally optimized construct

Other examples are the problem of finding fin design and fin spacing that match to optimal performance of heat transfer systems in a variety of cases and under various constraints (Refs. [64-68]).

The influence of irregularities upon heat transfer has been studied by Blyth and Pozrikidis [69], while Zimparov [70,71] addressed the effect of corrugated tubes as a passive augmentation technique for heat transfer.

Optimization of the thermal design of electronic equipment is crucial for the maximization of cooling (e.g., Mereu et al. [72]; Ogiso [73]). Ghodoossi and Egrican [74] used the constructal method for defining a conductive tree-network for the purpose of electronics cooling. Gosselin and Bejan [75] addressed the problem of optimizing the geometry of an electromagnet (shape of the coil, number of cooling disks, and the amount of high conductivity material) by maximizing at the same time its magnetic and thermal performance.

As an example of surface heat transfer optimization Wechsatol et al. [54] developed a tree-shaped flow path for cooling a diskshaped body by convection for the best combination of flow and thermal resistances. The competing flow architectures show a sharp transition between the radial and the more complex architectures (dendritic). Xia et al. [76] that performed heat conduction optimization have also found dendritic flow structures based on the principle of biological evolution.

Silva et al. [77,78] have addressed the optimal distribution of discrete heat sources on a surface for maximum heat transfer with natural or forced convection. Both the analytical and the numerical results converged in defining a multiscale and robust solution for the placement of the heat sources. The principle of "optimal distribution of imperfection" has been applied by Abu-Hijleh [79] to the reduction of natural convection through the optimal placement of baffles around a horizontal cylinder.

The effect of length scale on the maximization of heat transfer density was analyzed by Bejan [80] who stressed the importance of the length scale that comes from the observation that every fluid packet and every volume element must be used for the purpose of transferring heat in the optimization of heat transfer. Results of optimization of two configurations (parallel plates and spheres) based on the method of the intersection of the asymptotes, are presented under the new aspect that in the limit of decreasing length scales the boundary layers disappear. Additional analysis of the problem of the multiscale heat transfer was pre- sented by Alharbi and Pence [81] and Luo et al. [82].

Constructal theory has also been applied to the field of chemical engineering. Azoumah et al. [83] have defined optimized constructal tree-shaped networks for heat and mass transfer in porous solid-gas reactors, while Rivera-Alvarez and Bejan [84] have optimized the temporal and spatial structure of adsorptiondesorption processes for maximal packing of mass transfer into a fixed space, and for minimal overall pumping power (see also Pence [85]).

Constructal theory can also be used as a guide in the search for optimal structure in power and refrigeration systems. In his books, Bejan $[1,2]$ shows how to assemble engines or low-temperature machines in order to improve global efficiency under specified constraints.

In civil engineering, mechanical strength is an important consideration in the presence of sudden thermal attack (fire). Lorente and Bejan [86] and Gosselin et al. [87] have addressed combination of heat flow and strength for the optimization of the geometry and internal structure of a vertical insulating wall in what represents the first steps towards the constructal design of multiobjective architectures.

Several authors [88-98] have proposed constructal structures for maximum heat transfer density and power density (fuel cells). Costa [99] used heatlines and masslines for the visualization of heat and mass transfer patterns. Thermodynamic optimization of environmental control systems of a aircraft for the minimal power requirement was addressed by Ordonez and Bejan [100].

All these engineering applications illustrate how the constructal flow architectures are deduced from principle, unlike in fractal geometry where algorithms are assumed. Although constructal theory has been developed first for engineered systems, its field of application has been extended to a wide range of natural systems, animate or inanimate.

4.2 Flows in Nature. Rivers are large scale natural flows that play a major role in the shaping of the Earth's surface. River morphology exhibits similarities that are documented extensively in geophysics treatises. For example, Rosa [101] in a recent review article gives a broad list of allometric and scaling laws involving the geometric parameters of the river channels and of the river basins. Examples of such correlations are Hacks's law, $L$ $\propto A^{h}$, which correlates the stream length $L$, with basin area $A$, and 


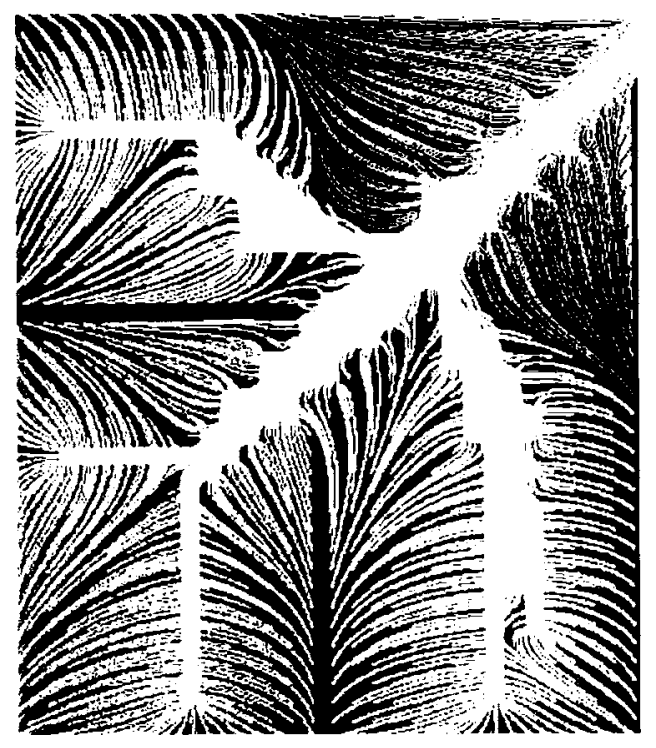

Fig. 7 Constructal treelike structure of superficial flow from an area to a point

Horton's Law, which states that the ratio of the number of tributary streams of consecutive order, $n_{i} / n_{i+1}$, is nearly independent of order.

Other impressive features of river morphology are the sinusoidal shape of river channels, which the buckling wavelength $(\lambda)$ is proportional to the channel width $\lambda \sim W[12]$, which, in turn is proportional to the maximum depth, $W \sim d$. Constructal theory links geometry to performance of river flow and explains how this geometric relations result from the minimization of global resistance [1]

River channels are round or nearly round. The same occurs in living structures (blood vessels, pulmonary airways, etc.). Calculations show that the flow resistances decrease as the shape becomes rounder. Although the round shape is the best, the nearly round shapes perform almost as well (Refs. $[1,8]$ ).

Constructal theory views the naturally occurring flow structures (their geometric form) as the end result of a process of area to point flow access optimization with the objective of providing minimal resistance to flow. For example, the features of the river drainage basins can be anticipated based on the area-to-point flow access optimization presented in Sec. 2. The generation of dendritic patterns of low resistance channels can be understood based on a simple model of surface erosion together with a principle that is invoked at every step. The model assumes that changes in the river channel are possible because finite portions (blocks) can be dislodged and entrained in the stream. As a rule, every square block of area $D^{2}$ and height $w$, is dislodged when the pressure difference across the block surpasses the critical force needed to dislodge it, i.e., $\Delta P D w>\tau D^{2}$ (Bejan [1], Errera and Bejan [102]). The flow resistance decreases with block removal. Further increase in the flow rate may create the conditions for the removal a second block and for the repetition of the process. A macroscopic treelike structure emerges progressively (see Fig. 7), while the global flow resistance decreases.

Constructal theory has been also applied to a model of the long-term behavior (climate) of the atmospheric and oceanic circulation that is the largest flow system on Earth (Bejan and Reis [103]; Reis and Bejan [104]). The method consisted of viewing the Sun-Earth-Universe assembly as an extraterrestrial power plant the power output of which is used for the purpose of forcing the atmosphere and hydrosphere to flow. In the model, the earth surface temperature is time independent. It is averaged over the daily and annual cycles, and is represented by two temperatures

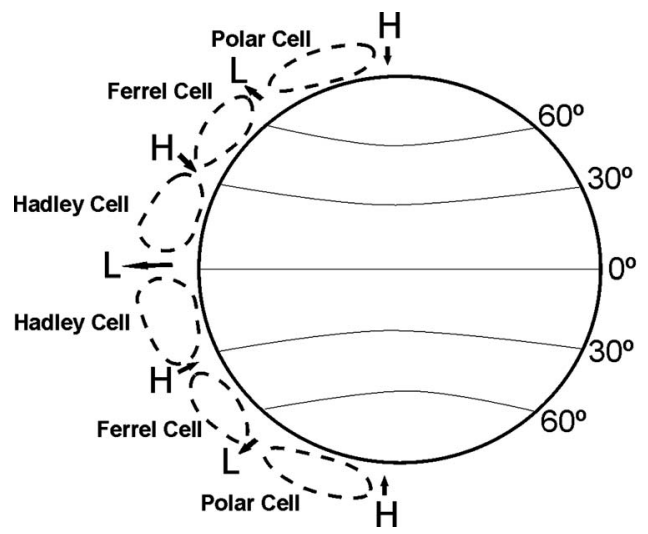

Fig. 8 Long-term meridional circulations on Earth represented by the Polar, Ferrel, and Hadley cells

$\left(T_{H}, T_{L}\right)$ that correspond to the equatorial and polar zones $\left(A_{H}, A_{L}\right)$. The excess heat $q$, collected in the equatorial zone $(H)$ is transported to the polar some $(L)$ by the Earth's circulations. The current $q$, depends on the surface allocation ratio $x=A_{H} /\left(A_{L}+A_{H}\right)$, that is the object of optimization. The mechanism by which the generated power is dissipated into heat by the movement of the atmosphere and the oceans is buoyancy driven convection. From the constructal point of view, the global circulation represents a flow geometry that is the result of the maximization of global performance subject to global constraints. The heat current is maximum for the surface allocation ratio $x=0.35$ (Bejan and Reis [103]). This indicates that the flow configuration that matches $x$ $=0.35$ is the one that performs the best with respect to the heat transport from the equatorial belt to the polar caps.

Improvements on this model led to a further important results (Reis and Bejan [104]). The latitude of the boundary between the Haddley and the Ferrel cells defining the long-term meridional atmospheric circulation, and the boundary between the Ferrel and the Polar cells can be determined with reasonable accuracy (see Fig. 8). Additionally, the average temperature of the Earth surface, the convective conductance in the horizontal direction, as well as other parameters defining the latitudinal circulation also matched the observed values.

The constructal law has also been applied to a model of global circulation at the daily scale (Reis and Bejan [104]). At optimal performance, the average temperature difference $T_{H}-T_{L}$ between day and night is of the order of $7 \mathrm{~K}$. This agrees with the order of magnitude of the average diurnal amplitudes observed on earth, which for the maritime areas is around $3 \mathrm{~K}$ and for continental areas is around $10 \mathrm{~K}$. Another important aspect is that the average temperature of the earth surface that results from diurnal optimization is $283.9 \mathrm{~K}$. This is practically the same as the average temperature found based on long-term analysis $(283.5 \mathrm{~K})$. The entropy generation rate calculated on the diurnal scale has the same value as that calculated for the long-term scale. The ways in which the variables used in these two calculations were derived are very different. For the long term, the heat current was determined as function of the earth partition $x$, while for the diurnal scale it was determined as a function of the Ekman number, Ek, which involves the earth rotation velocity, the height of the friction layer and the fluid flow velocity. The maximum of the entropy generation rate is located close to the point of optimum performance, but does not coincide with that point. The variables defining the properties of the friction layer have values of the same order of magnitude as those determined for the long term. The diurnal heat current between the illuminated and dark hemispheres is roughly 6 or 7 times lower than the long-term poleward current. However, both the convective conductance in the horizontal direction and the conductivity have values of the same 


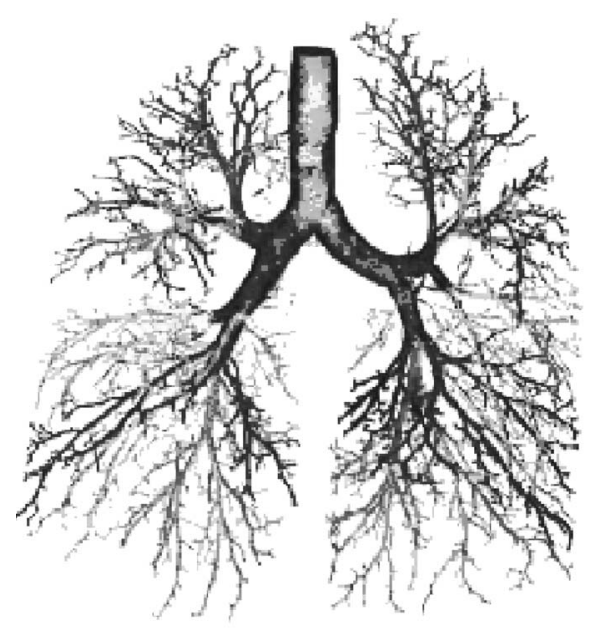

Fig. 9 Human lung airway tree has 23 bifurcations and is an optimized structure for oxygen and carbon dioxide transport

order as those obtained for the long term case.

Cracks usually form in shrinking soil (mud) cooled by forced convection. Based on the constructal law, i.e., the thought that the flow structure that develops in the soil must allow the maximum cooling or mass transfer effect it was shown (see Refs. [1,105]) that the crack lattice length scale must decrease as the wind speed and the initial excess temperature increase, which is in agreement with observations. Bisio and Rubatto [106] who found that cracks are denser where the conductive-convective effect is more intense and/or the initial departure from steady state is greater confirmed this result.

Miguel [107] in a recent review paper addresses the formation of dendritelike patterns in trail systems, plant roots and bacterial colonies.

4.3 Flows in Living Structures. Every living or engineered flying structure performs best when the power that is required for maintaining it in the air and for overcoming drag is minimum. For optimal performance the cruising speeds of flying structures must be proportional to the $1 / 6$ power of their body mass (Bejan $[1,108])$. This result is in good agreement with the cruising speeds of structures ranging from the house fly to the largest airplanes [1].

This same argument of minimum power expenditure applied to pulsating internal flows in animals led to relationships between rhythm and animal body size. Bejan [1] has addressed the rhythm of respiration in animals in relation to the body size and found that the breathing time increases with the animal body size raised to a power of $1 / 4$, which is also in good agreement with the biological observations. In the same way, the optimal heart beating frequency is approximately proportional to the square of the metabolic rate [1]. Related to this is the proportionality between body heat loss and body size raised to the power 3/4 (see Refs. [1,32]). Other constructal predictions of allometric laws can be found in Bejan [1].

The respiratory system is basically a fluid tree that starts at the trachea and bifurcates 23 times before reaching the alveolar sacs. The reason for the existence of just 23 bifurcations in the respiratory tree (Fig. 9) has remained unexplained in the physiology literature. Did this special flow architecture develop by chance, or does it represent the optimum structure for the lung's purpose, which is the oxygenation of the blood?

The search for the flow configuration that could transport oxygen from one opening (the entrance of the trachea) to the alveolar surface, and remove the carbon dioxide from the alveoli with the lowest resistance, has been pursued by Reis et al. [109] based on the constructal law. The problem involves the trade-off between

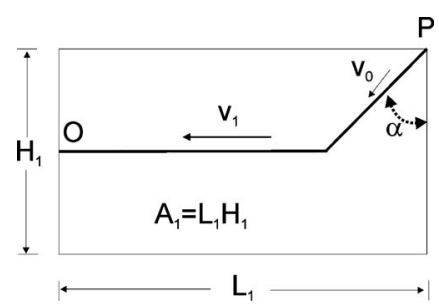

Fig. 10 The constructal route for minimum travel time between points $P$ and $O$, using two modes of locomotion of different speeds, $v_{1}$ and $v_{2}$

the convective flow resistance of the bronchial tree and the total resistance to oxygen diffusion in the alveoli. The constructal relations defining the ratios between consecutive channel diameters and lengths, together with the fluid properties, have been used in the analysis. The main theoretical result is that the best oxygen access to the tissues is performed by a flow structure composed of ducts with 23 levels of bifurcation. The same structure has been shown to be optimal for carbon dioxide removal as well. At the end of the smallest duct, spaces exist (alveolar sacs) from which the oxygen diffuses to the tissues, and in which the carbon dioxide that is removed from the tissues diffuses before reaching the bronchial tree that transports it to the surrounding air. The optimized number of bifurcation levels matches the 23 levels that the physiology literature indicates for the human bronchial tree.

In addition, the constructal optimization [109] also predicted the dimension of the alveolar sac, the total alveolar surface area, the total alveolar volume, and the total length of the airways. These values agree at least in an order of magnitude sense with the values found in the physiology literature. Furthermore, it was shown that the length defined by the ratio between the square of the first airway diameter and its length is constant for every individual of the same species, and is related to the characteristics of the space allocated for the respiratory process. This number is univocally determined by a nondimensional geometric number, $A L / V$, which involves the characteristics of the space allocated to the respiratory system, namely the total alveolar area, $A$, the total volume $V$, and the total length of the airways, $L$.

4.4 Flows in Transportation and Economics. Our society established connections, links, and networks with the purpose of exchanging goods, energy, and information. These spatially distributed patterns are everywhere: transportation routes, urban growth, energy, financial and communication networks. Objective, freedom to morph and constrains are essential for the generation of structure. The primary objective for movement of individuals and goods is minimum travel time. Constraints are the speeds of the means of locomotion. Bejan [110] in his first 1996 constructal paper noted that the traffic patterns have evolved in time as a result of a process of optimization. When the only means of locomotion was walking, the area-to-point pattern was radial and matched the straight-line solution. However, when the horsedriven carriage appeared, people had two modes of locomotion: walking with velocity $v_{0}$ and riding in a carriage with velocity $v_{1}$. The carriage had to follow special paths, otherwise the area covered by beaten tracks would leave no space for the inhabitants and their land properties. The modern problem is one of bringing the street near a small but finite-size group of inhabitants who would have to walk in order to reach the street. A finite length of street has to be allocated to each area element, and these street lengths must be connected in an optimal way such that the travel time of the entire population is minimum (see Fig. 10).

If we consider the area $A_{1}=H_{1} L_{1}$, the optimum aspect ratio for the first construct is $\left(H_{1} / L_{1}\right)_{\mathrm{opt}}=\left(2 v_{0}\right) /\left(f_{1} v_{1}\right)$, with $f_{1}=\cos \alpha_{1}$ and $\left(\alpha_{1}\right)_{\mathrm{opt}}=\sin ^{-1}\left(v_{0} / v_{1}\right)$ (see Refs. [1,110]). Similarly to the solution of the problem of area-to-point flow (Sec. 2), if instead of mini- 
mizing the longest travel time, i.e., the time spent for moving between points $\mathrm{P}$ and $\mathrm{O}$, we minimize the average travel time between the points in $A_{1}$ and $\mathrm{O}$ we arrive at the same optimal geometry. The optimal features of higher order assemblies lead to constructal rules like $\left(H_{i} / L_{i}\right)=v_{i-1} /\left(f_{i} v_{i}\right)$, and $\left(\alpha_{1}\right)_{\mathrm{opt}}$ $=\sin ^{-1}\left(v_{i-1} / 2 v_{1}\right)$ and $\left(t_{i}\right)_{\min }=2\left(f_{i} A_{i} / v_{i-1} v_{i}\right)^{1 / 2}$. Tree-dimensional volume-to-point access can be optimized in a completely analogous manner $[1,40,110]$.

A similar kind of optimization has been applied to the production of customized goods. A product platform is defined as a set of common components, modules or parts from which a stream of derivative products are created. Hernandez et al. [111] formulated the design of platforms for customizable products as a problem of optimization of access in a geometric space. This approach allowed them to develop systematically hierarchic product platforms with multiple levels of commonality.

Constructal theory has also been applied to spatial economics. Here the purpose is finding the minimum cost in transporting goods proceeding from one point (producers or distributors) to every point in a finite territory (consumers). Streams of goods play the role of flows while cost is the equivalent of resistance. Constructal rules for designing optimal transportation tree-shaped networks are presented in Refs. [1,14]. If instead of minimizing cost, the objective is to maximize revenue, the size of the elemental area where consumers are located may be predicted [14]. In spatial economics the law of parsimony that has been used with good results [1] and is equivalent of the constructal law. In fact, the similarities between the spatial structures of physical and economic flows spring out of the same deterministic principle.

\section{The Constructal Law and Entropy Generation Mini- mization}

Engineered systems are designed with a purpose. Each system must force its flows to follow the thermohydrodynamic paths that serve the global objective. To select the appropriate flow paths from the infinity of possible paths is the challenge. The rate of entropy generation is a measure of how internal flows deviate from the ideal limit of flow without resistances, or without irreversibility. The constructal law calls for optimal organization that maximizes internal flow access. Optimal flow organization minimizes entropy generation and therefore maximizes the system's performance. The method of entropy generation minimization (EGM) has been recognized in engineering and is now wellestablished $[12,13]$. Constructal theory argues that flow shapes and structures occur in nature in the same way (e.g., Sec. 4) and the principle is the Constructal Law.

To see the relationship between EGM and the Constructal Law note that the flows occurring in nature and engineered systems are dissipative. These flows generate entropy, and most may be described simply by

$$
R=V / I
$$

where $V$ is the potential that drives the current $I$, and $R$ is the resistance to flow. These flows generate entropy at the rate

$$
\dot{S}_{\mathrm{gen}}=V I / T
$$

where $T$ is the thermodynamic temperature. Equation (12) allows us to express the resistance as

$$
R=T \dot{S}_{\mathrm{gen}} / I^{2}
$$

In view of Eqs. (11) and (13), minimizing the flow resistance for a specified current $I$ corresponds to minimizing the entropy generation rate. This shows how the constructal law and the minimization of entropy generation are connected. The constructal law goes further and focuses on the generation of the flow configuration. It brings design (drawing, architecture) in the description of flow system physics. At the same time, the connection established by Eq. (13) is a reminder that, like the constructal law, the minimization of entropy generation rate in flow systems is a principle distinct from the Second Law. This deserves emphasis: the generation of entropy $\left(\dot{S}_{\text {gen }}\right)$ is the Second Law, while the generation of flow configuration (e.g., the minimization of $\dot{S}_{\text {gen }}$ ) is the Constructal Law.

For illustration, consider a flow tree with $N$ branching levels. The same current $I$ flows in each level of branching, that is $\sum_{i=I}^{n} I_{i}=\sum_{k=I}^{m} I_{k}=I$. If at a certain level of branching, the tree has $n$ ducts, the flow resistance at this level is

$$
R=\sum_{i=I}^{n} R_{i} I_{i} /(n I)
$$

The flow resistance at the same branching level may alternatively be expressed as a quadratic average, cf. Eq. (13),

$$
R=\sum_{i=I}^{n} R_{i} I_{i}^{2} / I^{2}
$$

Equations (14) and (15) lead to different values of the resistance unless $R_{i} I_{i}=V=$ const. Minimization of the tree resistance, as given by Eq. (14), at each level under the constraint of constant $I$, yields

$$
\sum_{i=1}^{n}\left(R_{i} /(n I)-\lambda_{1}\right) d I_{i}=0
$$

while minimization of flow resistance, as given by Eq. (15) gives

$$
\sum_{i=1}^{n}\left(2 R_{i} / I^{2}-\lambda_{2}\right) d I_{i}=0
$$

where $\lambda_{1}$ and $\lambda_{2}$ are constants. Equations (11)-(17) enable us to find the following relationships:

$$
R_{i} / n=R \quad n I_{i}=I \quad 1 / R=\sum_{i=I}^{n} 1 / R_{i} \quad V=R_{i} I_{i}
$$

In these relationships derived from the minimization of the flow tree resistance (constructal law) we can identify the well-know relationships of electric currents flowing in branched circuits. However, they hold for any tree where a current obeying Eq. (11) flows. In Eqs. (18) we find the general form of the law of equipartition of the resistances, which was highlighted in Sec. 2. The rate of entropy generation is constant at any branching level and is given by

$$
\dot{S}_{\text {gen }}=\sum_{i=1}^{n} R_{i} I_{i}^{2} / T=R I^{2} / T
$$

The minimal rate of entropy generation is given by Eq. (19) which, in view of Eq. (18), is achieved when Eqs. (14) and (15) lead to the same resistance.

The great physicist Feynman noted that "...minimum principles sprang in one way or another from the least action principle of mechanics and electrodynamics. But there is also a class that does not. As an example, if currents are made to go through a piece of material obeying Ohm's Law, the currents distribute themselves inside the piece so that the rate at which heat is generated is as little as possible. Also, we can say (if things are kept isothermal) that the rate at which heat is generated is as little as possible..." (Feynman [112]). Actually, the principle of least action accounts for point-to-point motion and cannot accommodate point-to-area and point-to-volume flows. We revisit this subject in Sec. 7.

In summary, the constructal law provides a unifying picture for point-to-area and point-to-volume flows. It also makes clear why living organisms in their struggle for lowering the rate of internal entropy generation have constructed flow trees for optimal flow access throughout their bodies, and throughout their societies. 


\section{Thermodynamic Formulation of the Constructal Law}

A summary of the preceding developments is provided by the formalism developed by Bejan and Lorente [8]. Thermodynamics is the theory of equilibrium states while constructal theory is the theory of the evolution toward equilibrium flow configurations. Equilibrium states spring out of the second law (e.g., the maximization of entropy in an isolated system) while equilibrium flow configurations spring out of the constructal law (the maximization of global flow access). This formal analogy bridges the gap between thermodynamics and constructal theory.

Constructal Theory $[1-3,110]$ began with the global objective(s) and the global constraint(s) of the flow system, and the fact that in the beginning the geometry of the flow is missing. Geometry is the big unknown. When the current $I$, is fixed, the objective is flow architectures with minimal pressure overall difference $(\Delta P)$, minimal overall flow resistance $(R)$, or minimal rate of entropy generation by fluid friction. There are two global constraints, one external and the other internal. The external constraint is the "system size," which is represented by the distance traveled by the flows, $L$. The internal global constraint is the "amount" invested in making the flow architecture that is the total volume $(V)$ of all the ducts of the flow structure. A flow must be guided. Flow means direction, geometry, and architecture, in addition to flow rate.

The evolution of flow configuration for point-to-point flows is a universal phenomenon, which manifests itself during any search for optimal flow architectures. According to constructal theory, the best flow path that makes the connection of one point (source, or sink) with an infinity of points (line, area, or volume) is shaped as a tree.

Changes in performance (in the global resistance $R$ ) can be achieved through changes in three categories:

I. Flow configuration;

II. Global external size, or covered territory, $L$;

III. Global internal size, or duct volume, $V$.

All the flow systems discussed so far have configurations that inhabit the three-dimensional hyperspace shown in Fig. 11(a). All the constant $L$ flow configurations that are possible make up the body visualized by the constant $V$ and constant $R$ cuts. The bottom figure shows the view of all the possible flow structures, projected on the base plane. Plotted on the $R$ axis is the global resistance of the flow system. The abscissa accounts for the total volume occupied by the ducts $(V)$; this is a global measure of how "porous" or "permeable" the flow system is. The constructal law is the statement that summarizes the common observation that flow structures that survive are those that morph (evolve) in one direction in time; toward configurations that make it easier for currents to flow. The first such statement was the following [1-3]: "For a finite-size system to persist in time (to live), it must evolve in such a way that it provides easier access to the imposed currents that flow through it." This statement refers strictly to structural changes under finite-size constraints. If the flow structures are free to change (free to approach the base plane in Fig. 11(a), they will move at constant $L$ and constant $V$ in the direction of progressively smaller $R$. If the initial configuration is represented by point 1 in Fig. 11(b), then a later configuration is represented by point 2 . The relation between the two configurations is

$$
R_{2} \leq R_{1}(\text { constant } L, V)
$$

If freedom to morph persists, then the flow structure will continue toward smaller $R$ values. Any such change is characterized by

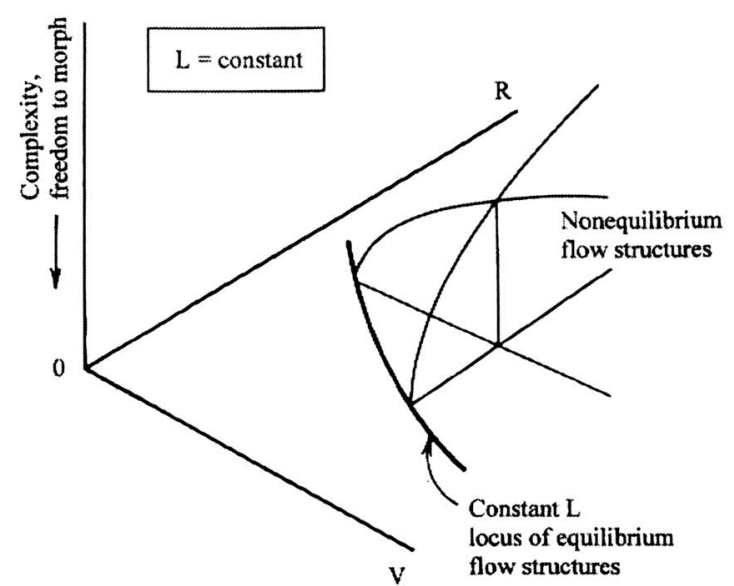

(a)

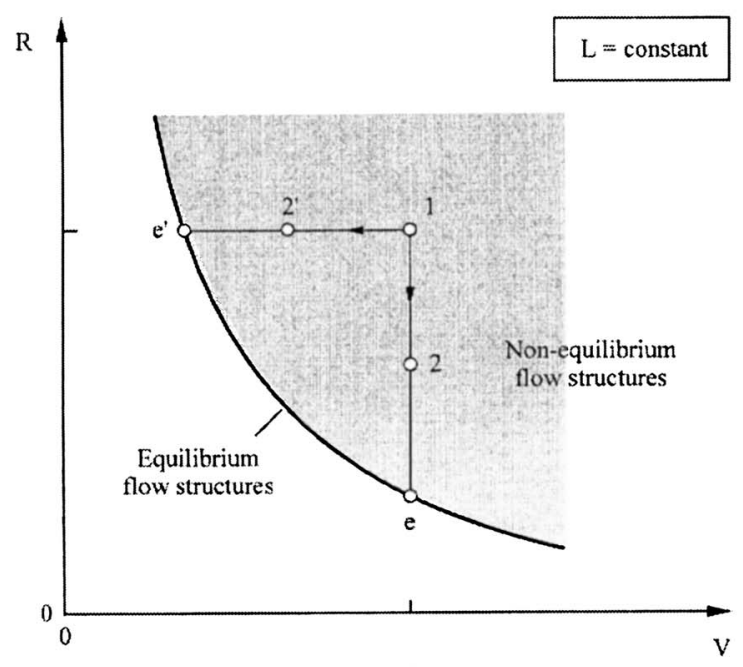

(b)

Fig. 11 Flow structure diagram for fixed external size $(L)$ (reprinted from Ref. [8] with permission)

$$
d R<0 \quad(\text { constant } L, V)
$$

The end of this migration is the equilibrium flow structure (point e), where the geometry of the flow enjoys total freedom. Equilibrium is characterized by minimal $R$ at constant $L$ and $V$. In the vicinity of the equilibrium point we have

$$
d R=0 \quad \text { and } \quad d^{2} R>0 \quad(\text { constant } L, V)
$$

The $R(V)$ curve shown in Fig. 11(b) is the edge of the cloud of possible flow architectures with the same global size $L$. The curve has negative slope because of the physics of flow: the resistance decreases when the flow channels would open up,

$$
\left(\frac{\partial R}{\partial V}\right)_{L}<0
$$

The constant $R$ cut through the configuration space shows another way of expressing the constructal law. If free to morph, the flow system will evolve from point 1 to point $2^{\prime}$ at constant $L$ and $R$. In the limit of total freedom, the geometry will reach another equilibrium, which is represented by point $\mathrm{e}^{\prime}$. The alternative analytical statement of the constructal law is 


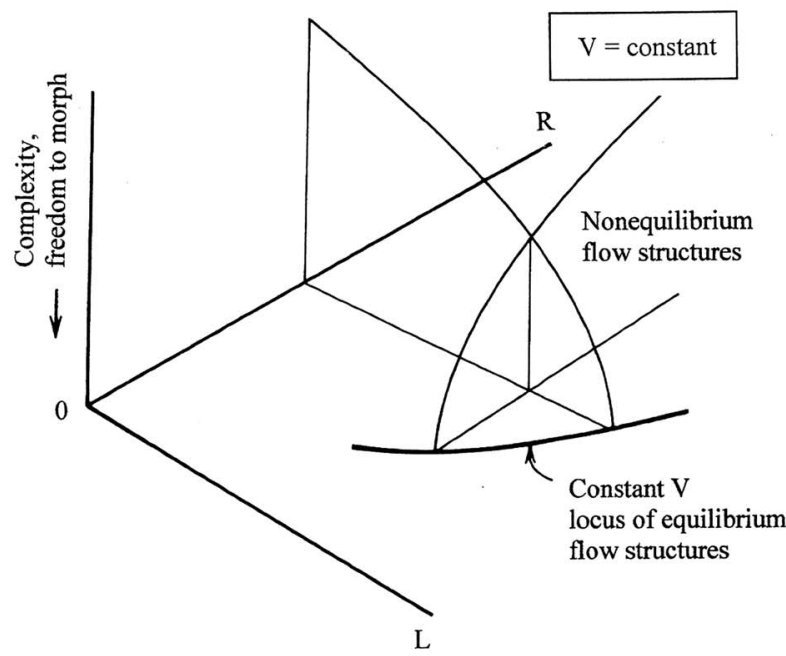

(a)

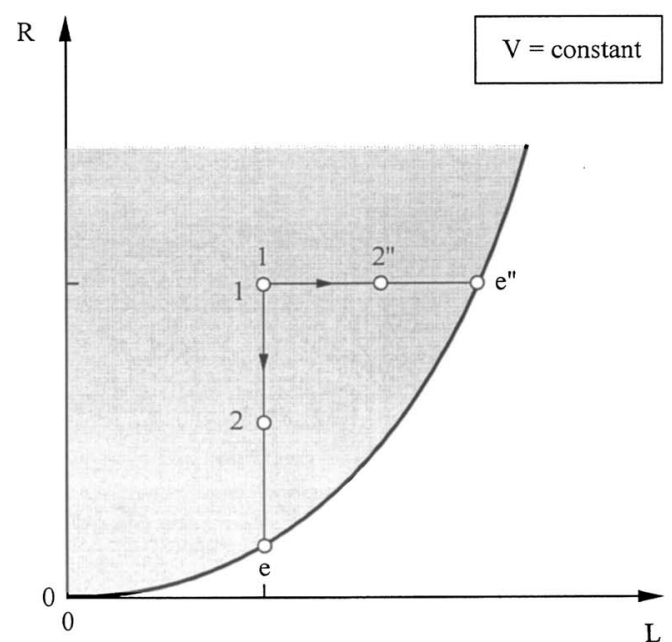

(b)

Fig. 12 Flow structure diagram for fixed internal size (duct volume $V$ ) (reprinted from Ref. [8] with permission)

$$
d V \leq 0 \quad(\text { constant } L, R)
$$

For changes in structure in the immediate vicinity of the equilibrium structure, we note

$$
d V=0 \quad \text { and } \quad d^{2} V>0 \quad(\text { constant } L, R)
$$

Paraphrasing the original statement of the constructal law, we may describe processes $1-2^{\prime}-e^{\prime}$ as follows: "For a system with fixed global size and flow resistance to persist in time (to live), it must evolve in such a way that its flow structure occupies a smaller fraction of the available space."

The constant $V$ alternative to Fig. 11 is shown in Fig. 12. The lower drawing is the projection of the space of possible flow architectures on the base plane $R-L$. The continuous line is the locus of equilibrium flow structures at constant $V$, namely, the curve $R(V)$ where

$$
\left(\frac{\partial R}{\partial L}\right)_{V}>0
$$

The fact that the slope is positive is flow physics: the flow resistance increases as the distance that must be overcome by the flow increases.
The constructal law statement can be read off in Fig. 12(b) in two ways. At constant $V$ and $L$, the evolution is from a suboptimal structure (point 1) to one that has a lower global resistance (point 2 ). If the flow geometry continues to morph freely, the structure approaches the equilibrium configuration (point e). In the vicinity of point e, the changes in flow structures are characterized by Eqs. (22).

If structural changes are made such that $R$ remains constant while $V$ is also fixed, then the evolution in Fig. 12(b) is from point 1 to point $2^{\prime \prime}$. Such changes mean that

$$
d L \geq 0 \quad(\text { constant } R, V)
$$

and that the constructal law statement becomes the following: In order for a flow system with fixed global resistance $(R)$ and internal size $(V)$ to persist in time, the architecture must evolve in such a way that it covers a progressively larger territory. Equilibrium is reached at point $\mathrm{e}^{\prime \prime}$. The changes in flow structures in the immediate vicinity of the equilibrium structure are such that the global external dimension at equilibrium is maximal,

$$
\left.d L=0 \quad d^{2} L<0 \quad \text { (constant } R, V\right)
$$

According to Eqs. (28), the constructal law states that the ultimate flow structure with specified global resistance $(R)$ and internal size $(V)$ is the largest. A flow architecture with specified $R$ and $V$ has a maximum size, and this global size belongs to the equilibrium architecture. A flow structure larger than this does not exist. This formulation of the constructal law has implications in natural design, e.g., the spreading of species and river deltas without access to the sea.

It is worth examining the ground covered so far. The original statement of the constructal law was about the maximization of flow access under global size constraints (external $L$, internal $V$ ), which in the present formulation means the minimization of global flow resistance. This behavior is illustrated by the structural changes $1-2-e$ in Figs. 11(b) and 12(b), and by Eqs. (21) and (22). In lay terms, this means survival by increasing efficiency. In time, irreversible flow structures are followed by less irreversible structures.

The alternative shown by the changes $1-2^{\prime \prime}-e^{\prime \prime}$ in Fig. $12(b)$ is survival by spreading: growth as the mechanism for persisting in time. The limit to growth is set by the specified constraints, in this case the fixed global flow resistance $R$ and the global internal size $V$.

The examples discussed so far showed that changes may occur in one category, or simultaneously in two or three. The simplest illustration is possible for the case of equilibrium flow architectures. For them the solid curves shown in Figs. 11(b) and 12(b) proclaim the existence of the fundamental relation $R(L, V)$, the differential of which is

$$
d R=Y_{L} d L+Y_{V} d V \quad \text { (equilibrium) }
$$

Physics requires that the first partial derivatives of $R$ have opposite signs, $Y_{L}>0$ and $Y_{V}<0$, as noted in Eqs. (26) and (23). Analytical expressions for these derivatives are available in simple cases. One example, is the global flow resistance of a T-shaped construct of round tubes with fully developed laminar flow where $R \sim A^{3 / 2} / V^{2}$, and $A$ (or $\sim L^{2}$ in this paper) is the area occupied by the construct. If the flow regime is turbulent, $R$ is proportional to $A^{7 / 4} / V^{5 / 2}$ (Bejan et al. [41]). The global resistance of an equilibrium flow structure can be decreased $(d R<0)$ through changes II and III, i.e., by making the structure occupy a smaller territory $(d L<0)$, and/or by endowing the structure with a larger internal flow volume $(d V>0)$.

In general, when the flow architecture has not reached equilibrium, $R$ can be decreased by means I, II, and III. The general version of Eq. (29) is 
Table 1 The analogy between the concepts, statements, and principles of thermodynamics and constructal theory [9]

\begin{tabular}{lc}
\hline \hline Thermodynamics & Constructal theory \\
\hline State & Flow architecture (geometry, \\
structure) \\
Process & Change of structure \\
Properties $(U, S, \mathrm{Vol}, \ldots)$ & $\begin{array}{c}\text { Global objective and global } \\
\text { constraints }(\mathrm{R}, \mathrm{L}, \mathrm{V}, \ldots)\end{array}$ \\
Equilibrium state & Equilibrium flow architectur \\
Fundamental relation, & Fundamental relation, \\
$U(S$, Vol,..$)$ & $R(L, V, \ldots)$ \\
Constrained equilibrium states & Nonequilibrium architectures \\
Removal of constraints & Increased freedom to morph \\
Energy minimum principle: & $\begin{array}{c}\text { Maximization of flow access } \\
\text { principle }(\text { Constructal Law): }\end{array}$ \\
$U$ minimum at constant $S$ and Vol & $R$ minimum at constant $L$ and $V$ \\
$S$ maximum at constant $U$ and Vol & $V$ minimum at constant $R$ and $L$ \\
& $L$ maximum at constant $V$ and $R$ \\
\hline \hline
\end{tabular}

$$
d R \leq Y_{L} d L+Y_{V} d V \quad \text { (nonequilibrium) }
$$

where the inequality sign refers to the time arrow of structural changes in a flow configuration that, at least initially, was not of the equilibrium type. It is instructive to review Eqs. (21), (24), and (27), to see that Eq. (30) is a concise statement of the three analytical formulations of the constructal law that we discussed so far: $R$ minimum at constant $L$ and $V ; V$ minimum at constant $R$ and $L ; L$ maximum at constant $V$ and $R$.

Another way to summarize the analytical formulation that we have just constructed is by recognizing the analogy between the analytical constructal law and the analytical formulation of classical thermodynamics $[2,112,114])$. The analogy is presented in Table 1. It is stressed further by Figs. $9(a)$ and $10(a)$, which are well known but labeled differently in classical thermodynamics (e.g., Bejan [2], pp. 241 and 244).

\section{How the Constructal Law Fits Among Other Funda- mental Principles}

System evolution in space and time is governed by fundamental principles. Classical and relativistic dynamics, electromagnetism and nonrelativistic quantum mechanics spring out of the principle of least action (Feynman [112]). Symmetry is another fundamental concept evinced by Noether's theorem, which states, "Every continuous symmetry of the dynamical equations and potential of the system implies a conservation law for the system" (e.g., symmetry under time reversal implies conservation of energy, translational symmetry implies conservation of linear momentum, etc.) (see Callen [113]). Classical optics follows from the principle of minimum travel time taken by light between two points. The second law governs internal evolution of isolated systems by defining the sequence of equilibrium states that match successive relaxation of internal constraints.

Symmetry and the principles of least action and minimum travel time account for motion from point to point. The second law predicts properties of systems at equilibrium. None of these principles rationalises the occurrence of shape and nonequilibrium internal (flow) structure of systems. In fact, these geometrical features are assumed in advance as constraints to the system dynamics. In spite of being ubiquitous in nature, they are considered to be the result of chance.

Constructal theory accounts for the huge variety of natural structures and shapes and unifies them in the light of the constructal law. Chance leaves its mark in every natural system, but determinism plays here the fundamental role. The field of application of the constructal law is disjoint to those of other principles as is in the heart of nonequilibrium, flow systems, entropy generation, and evolution in time. Unlike minimum travel time and least action principles that account for motion from point to point, the reach of constructal theory is far broader. It addresses motion from volume (or area) to point and vice versa. The principle of least action constraints motion from point to point to follow a special trajectory among an infinity of possible trajectories, while the constructal principle organizes motion from volume (or area) to point in a special flow architecture out of infinity possible architectures.

Natural systems are complex and change in many ways. In the past, scientists realized that for understanding nature they had to focus their attention on simple and homogenous systems. Motion, as the change of relative position with time, is the ubiquitous phenomenon that called for explanation, and the principle of least action is the principle that unified motions from point to point in a common picture. The constructal law is its counterpart, by allowing systems with complex internal flows to be described and understood under a unified view.

Unlike the usual direction of scientific inquiry, which divides systems into smaller and simpler subsystems (analysis), constructal theory proceeds from the elemental to the complex by successively assembling blocks (construction), which are elemental at the stage considered but are structured and complex when viewed from the previous stage.

The parallelism between engineering and nature becomes evident (e.g., Refs. $[115,116])$. Engineers create systems with purpose and try to increase their performance in time. Systems have to evolve in time to approach this goal because reaching optimal performance takes time. Natural systems, animate and inanimate, also exist with purpose. The purpose of a stem is to hold and provide leaves with water and nutrients, while that of river basins is to collect superficial water and deliver it into oceans. Unlike engineering, nature has been morphing its shapes and structures for billions of years. Nature uses not method, but time, evolution, tries, errors, and selecting every time the solutions that bring it closer to better flow access. Nevertheless, as parts of each of us (man + machine species), engineered systems evolve according to the same law as natural flow systems, which goes to show that to engineer is natural.

\section{Conclusion}

There is no limit to this subject. It is just a different point of view of things, which constructal theory proposes. It is a point of view of the engineer about the forms of nature. Constructal theory proposes to see the trees, the human bodies, like machines that are subjected to constraints, which are constructed with a goal, an objective, which is to obtain maximum efficiency.

This constructal theory is about the method of constructing such machines, which attain optimally their objective. It proposes a different look at corals, birds, atmospheric flow and, of course, at the machines built by engineers.

In this paper we gave an overview of the applications of the constructal theory, which extends from engineering to natural systems, alive and inanimate and to human activities like organization of cities, transportation, and economics. Wherever something flows, a flow architecture emerges, which can be understood in the light of constructal theory. The many examples presented here illustrate how the symbiosis between flow dynamics and geometry is the heart of constructal theory. This theory has proved to be useful in describing complex flow systems and the field of its potential applications is open to researchers from engineering and natural and social sciences. In the writer's view, constructal theory is essential to those who strive to describe natural systems in a quantitative fashion.

Constructal theory also provides a new way of thinking with epistemological and philosophical implications (Rosa [117], Patrício [118], Bejan [119]). From the epistemological point of view, its method proceeds from the simple to the complex, against the usual paradigm of science that calls for the deconstruction of the complex to reach the elemental. The philosophical consequences are also obvious and important; constructal theory gives chance a 
secondary role in the evolution of natural systems. Constructal theory assigns the major role to determinism, and contributes significantly to the debate on the origin of living systems.

\section{Nomenclature}

$$
\begin{aligned}
A & =\text { area }(\mathrm{m} 2) \\
\mathrm{Be} & =\text { Bejan number } \\
c_{P} & =\text { specific heat }\left(\mathrm{J} \mathrm{kg}^{-1} \mathrm{~K}^{-1}\right) \\
D & =\text { thickness, spacing, }(\mathrm{m}) \\
H & =\text { height, width }(\mathrm{m}) \\
I & =\text { electric current }(\mathrm{A}) \\
K & =\text { permeability }\left(\mathrm{m}^{2}\right) \\
L & =\text { length }(\mathrm{m}) \\
\dot{m}^{\prime} & =\text { mass flow rate }\left(\mathrm{kg} \mathrm{s}^{-1}\right) \\
\mathrm{Nu} & =\text { Nusselt number } \\
P & =\text { pressure }(\mathrm{Pa}) \\
\mathrm{Pr} & =\text { Prandtl number } \\
q & =\text { heat transfer rate }\left(\mathrm{J} \mathrm{s}^{-1}\right) \\
R & =\text { resistance }(\text { generic }), \text { electric resistance }(\Omega) \\
\dot{S}_{\mathrm{gen}} & =\text { entropy generation rate }\left(\mathrm{J} \mathrm{K}^{-1} \mathrm{~s}^{-1}\right) \\
T & =\text { temperature }(\mathrm{K}) \\
V & =\text { volume }\left(\mathrm{m}^{3}\right) \\
V_{e} & =\text { electric potential difference } \\
\mathrm{V} & =\text { velocity }\left(\mathrm{m} \mathrm{s}^{-1}\right) \\
\alpha & =\text { angle }(\mathrm{rad}) \\
\rho & =\text { density }\left(\mathrm{kg} \mathrm{m}^{-3}\right) \\
\mu & =\text { dynamic viscosity }\left(\mathrm{N} \mathrm{s} \mathrm{m}^{-2}\right) \\
\nu & =\text { kinematic viscosity }\left(\mathrm{m}^{2} \mathrm{~s}^{-1}\right)
\end{aligned}
$$

\section{References}

[1] Bejan, A., 2000, Shape and Structure, From Engineering to Nature, Cambridge University Press, Cambridge, UK.

[2] Bejan, A., 1997, Advanced Engineering Thermodynamics, 2nd ed., Wiley, New York, Chap. 13

[3] Bejan, A., 1997, "Constructal-Theory Network of Conducting Paths for Cooling a Heat Generating Volume," Int. J. Heat Mass Transfer, 40, pp. 799-816.

[4] Bejan, A., 1997, "Theory of Organization in Nature: Pulsating Physiological Processes," Int. J. Heat Mass Transfer, 40, pp. 2097-2104.

[5] Bejan, A., 1997, "How Nature Takes Shape," Mech. Eng. (Am. Soc. Mech. Eng.), 119(10), pp. 90-92.

[6] Bejan, A., 1997, "Constructal Tree Network for Fluid Flow Between a FiniteSize Volume and One Source or Sink," Rev. Gen. Therm., 36, pp. 592-604.

[7] Bejan, A., and Tondeur, D., 1998, "Equipartition, Optimal Allocation, and the Constructal Approach to Predicting Organization in Nature," Rev. Gen. Therm., 37, pp. 165-180.

[8] Bejan, A., and Lorente, S., 2004, "The Constructal Law and the Thermodynamics of Flow Systems With Configuration," Int. J. Heat Mass Transfer, 47, pp. 3203-3214.

[9] Bejan, A., and Lorente, S., 2004, "Equilibrium and Nonequilibrium Flow System Architectures," Heat Technol., 22(1), pp. 85-92.

[10] Bejan, A., 1999, "A Role for Exergy Analysis and Optimization in Aircraft Energy-System Design,” ASME Advanced Energy Systems, 39, pp. 209-218.

[11] Bejan, A., 2002, "Fundamentals of Exergy Analysis, Entropy Generation Minimization, and the Generation of Flow Architecture," Int. J. Energy Res., 26(7), pp. 545-565.

[12] Bejan, A., 1982, Entropy Generation Through Heat and Fluid Flow, Wiley, New York.

[13] Bejan, A., 1996, Entropy Generation Minimization, CRC Press, Boca Raton.

[14] Bejan, A., Badescu, V., and De Vos, A., 2000, "Constructal Theory of Economics Structure Generation in Space and Time," Energy Convers. Manage., 41, pp. 1429-1451.

[15] Bejan, A., and Errera, M. R., 1997, "Deterministic Tree Networks for Fluid Flow: Geometry for Minimal Flow Resistance Between a Volume and One Point," Fractals, 5(4), pp. 685-695.

[16] Lewins, J., 2003, "Bejan's Constructal Theory of Equal Potential Distribution," Int. J. Heat Mass Transfer, 46, pp. 1451-1453.

[17] Bejan, A., and Dan, N., 1999, "Two Constructal Routes to Minimal Heat Flow Resistance via Greater Internal Complexity," ASME J. Heat Transfer, 121, pp 6-14.

[18] Bejan, A., and Dan, N., 1999, "Constructal Trees of Convective Fins," ASME J. Heat Transfer, 121, pp. 675-682.

[19] Ledezma, G. A., and Bejan, A., 1998, "Constructal Three-Dimensional Trees for Conduction Between a Volume and One Point," ASME J. Heat Transfer, 120, pp. 977-984.

[20] Bejan, A., 2004, Convection Heat Transfer, 3rd ed., Wiley, New York.

[21] Bejan, A., 2003, "Simple Methods for Convection in Porous Media: Scale
Analysis and the Intersection of Asymptotes," Int. J. Energy Res., 27, pp. 859-874.

[22] Battacharjee, S., and Grosshandler, W. L., 1988, "The Formation of a Wall Jet Near a High Temperature Wall Under Microgravity Environment," ASME Heat Transfer Division, 96, pp. 711-716.

[23] Petrescu, S., 1994, "Comments on the Optimal Spacing of Parallel Plates Cooled by Forced Convection," Int. J. Heat Mass Transfer, 37, p. 1283.

[24] Bejan, A., 1999, "How Nature Takes Shape: Extensions of Constructal Theory to Ducts, Rivers, Turbulence, Cracks, Dendritic Crystals and Spatial Economics," Int. J. Therm. Sci., 38, pp. 653-663.

[25] Bejan, A., 2001, "Constructal Theory: An Engineering View on the Generation of Geometric Form in Living (Flow) Systems," Comments on Theoretical Biology, 6(4), pp. 279-302.

[26] Borrvall, T., Klarbring, A., Petersson, J., and Torstenfelt, B., 2002, “Topology Optimization in Fluid Mechanics," Proceedings of Fifth Congress on Comp. Mech.

[27] Nakayama, W., 2003, "A Methodology to Work on Geometrically Complex Heat Systems: The Cases of Heat Conduction Through Composite Slabs," Int J. Heat Mass Transfer, 46, pp. 3397-3409.

[28] Brod, H., 2003, "Residence Time Optimised Choice of Tube Diameters and Slit Heights in Distribution Systems for non-Newtonian Liquids," J. NonNewtonian Fluid Mech., 111, pp. 107-125.

[29] Bejan, A., 1998, "Questions in Fluid Mechanics: Natural Tree-Shaped Flows," J. Fluids Eng., 120, pp. 429-430.

[30] Bejan, A., 1998, "Constructal Theory: From Thermodynamic and Geometric Optimization to Predicting Shape in Nature," Energy Convers. Manage. 39(16-18), pp. 1705-1718.

[31] Bejan, A., 2000, "From Heat Transfer Principles to Shape and Structure in Nature: Constructal Theory," J. Heat Transfer, 122, pp. 430-449.

[32] Bejan, A., 2001, "The Tree of Convective Heat Streams: Its Thermal Insulation Function and the Predicted 3/4-Power Relation Between Body Heat Loss and Body Size," Int. J. Heat Mass Transfer, 44, pp. 699-704.

[33] Bejan, A., 2003, "Constructal Theory: Tree-Shaped Flows and Energy Systems for Aircraft," J. Aircr., 40(1), pp. 43-48.

[34] Bejan, A., 2003, "Constructal Tree-Shaped Paths for Conduction and Convection,” Int. J. Energy Res., 27, pp. 283-299.

[35] Bejan, A., 2003, "Flows in Environmental Fluids and Porous Media," Int. J. Energy Res., 27, pp. 825-846.

[36] Bejan, A., and Errera, M. R., 2000, "Convective Trees of Fluid Channels for Volumetric Cooling," Int. J. Heat Mass Transfer, 43, pp. 3105-3118.

[37] Bejan, A., and Errera, M. R., 1997, "Deterministic Tree Networks for Fluid Flow: Geometry for Minimal Flow Resistance Between a Volume and One Point," Fractals, 5(4), pp. 685-695

[38] Bejan, A., and Lorente, S., 2002, "Thermodynamic Optimization of Flow Architecture: Dendritic Structures and Optimal Sizes of Components," ASME $I M E C E$, International Mechanical Engineering Congress and Exposition, New Orleans, November 17-22, Vol. 3.

[39] Bejan, A., and Lorente, S., 2001, "Thermodynamic Optimization of Flow Geometry in Mechanical and Civil Engineering," J. Non-Equilib. Thermodyn., 26(4), pp. 305-354.

[40] Bejan, A., and Ledezma, G. A., 1998, "Streets Tree Networks and Urban Growth: Optimal Geometry for Quickest Access Between a Finite-Size Volume and One Point," Physica A, 255, pp. 211-217.

[41] Bejan, A., Rocha, L. A. O., and Lorente, S., 2000, "Thermodynamic Optimization of Geometry: T- and Y- Shaped Constructs of Fluid Streams," Int. J. Therm. Sci., 39, pp. 949-960.

[42] Rocha, L. A. O., and Bejan, A., 2001, "Geometric Optimization of Periodic Flow and Heat Transfer in a Volume Cooled by Parallel Tubes," ASME J. Heat Transfer, 123, pp. 233-239.

[43] Errera, M. R., and Bejan, A., 1999, "Tree Networks for Flows in Porous Media," J. Porous Media, 2, pp. 1-18.

[44] Almogbel, M., and Bejan, A., 2001, "Constructal Optimization of Nonuniformly Distributed Tree-Shaped Flow Structures for Conduction,” Int. J. Heat Mass Transfer, 44, pp. 4185-4195.

[45] Lorente, S., Wechsatol, W., and Bejan, A., 2002, "Tree-Shaped Flow Structures Designed by Minimizing Path Lengths," Int. J. Heat Mass Transfer, 45(16), pp. 3299-3312.

[46] Lorente, S., Wechsatol, W., and Bejan, A., 2003, "Optimization of TreeShaped Flow Distribution Structures Over a Disc-Shaped Area," Int. J. Energy Res., 27, pp. 715-723.

[47] Lorente, S., Wechsatol, W., and Bejan, A., 2004, "Tree-Shaped Flow Structures for Human-Scale and Small-Scales Applications," Heat Technol., 22(1), pp. 15-26.

[48] Rocha, L. A. O., Lorente, S., and Bejan, A., 2002, "Constructal Design for Cooling a Disc-Shaped Area by Conduction," Int. J. Heat Mass Transfer, 45, pp. 1643-1652.

[49] Neagu, M., and Bejan, A., 1999, "Constructal-theory Tree Networks of 'Constant' Thermal Resistance,” J. Appl. Phys., 86(2), pp. 1136-1144.

[50] Neagu, M., and Bejan, A., 1999, "Three-Dimensional Tree Constructs of 'Constant' Thermal Resistance,” J. Appl. Phys., 86(12), pp. 7107-7115.

[51] Wechsatol, W., Lorente, S., and Bejan, A., 2001, "Tree-Shaped Insulated Designs for the Uniform Distribution of Hot Water Over an Area," Int. J. Heat Mass Transfer, 44, pp. 3111-3123

[52] Wechsatol, W., Lorente, S., and Bejan, A., 2002, "Development of TreeShaped Flows by Adding New Users to Existing Networks of Hot Water Pipes," Int. J. Heat Mass Transfer, 45, pp. 723-733.

[53] Wechsatol, W., Lorente, S., and Bejan, A., 2002, "Optimal Tree-Shaped Net- 
works for Fluid Flow in a Disc-Shaped Body," Int. J. Heat Mass Transfer, 45(25), pp. 4911-4924.

[54] Wechsatol, W., Lorente, S., and Bejan, A., 2003, "Dendritic Convection on a Disc," Int. J. Heat Mass Transfer, 46, pp. 4381-4391.

[55] Wechsatol, W., Lorente, S., and Bejan, A., 2004, "Tree-Shaped Flow Structures: Are Both Thermal-Resistance and Flow-Resistance Minimisations Necessary?"' Int. J. Exergy, 1(1), pp. 2-17.

[56] Arion, V., Cojocari, A., and Bejan, A., 2003, "Constructal Tree Shaped Networks for the Distribution of Electric Power," Energy Convers. Manage., 44, pp. 867-891.

[57] Ordonez, J. C., Bejan, A., and Cherry, R. S., 2003, "Designed Porous Media: Optimally Nonuniform Flow Structures Connecting One Point With More Points," Int. J. Therm. Sci., 42, pp. 857-870.

[58] Bonjour, J., Rocha, L. A. O., Bejan, A., and Meunier, F., 2003, “Dendritic Fins Optimization for a Coaxial Two-Stream Heat Exchanger,” Int. J. Heat Mass Transfer, 47, pp. 111-124.

[59] Zamfirescu, C., and Bejan, A., 2003, "Constructal Tree-Shaped Two-Phase Flow for Cooling a Surface," Int. J. Heat Mass Transfer, 46(15), pp. 2785 2797.

[60] Reis, A. H., Miguel, A. F., and Aydin, M., 2004, "Constructal Design of a Porous Structure for Gas Transport From One Opening to a Surface," Applications of Porous Media, Proceeding of the International Conference on Applications of Porous Media, Évora, Portugal, A. H. Reis and A. F. Miguel, eds.

[61] Matos, R. S., Vargas, J. V. C., Laursen, T. A., and Bejan, A., 2004, "Optimally Staggered Finned Circular and Elliptic Tubes in Forced Convection," Int. J. Heat Mass Transfer, 47, pp. 1347-1359.

[62] Matos, R. S., Laursen, T. A., Vargas, J. V. C., and Bejan, A., 2004, "ThreeDimensional Optimization of Staggered Finned Circular and Elliptic Tubes in Forced Convection," Int. J. Therm. Sci., 43, pp. 477-487.

[63] Kraus, A. D., 2003, "Constructal Theory and the Optimization of Finned Arrays," Proceedings of the 2003 ASME International Mechanical Engineering Congress.

[64] Alebrahim, A., and Bejan, A., 1999, "Constructal Trees of Circular Fins for Conductive and Convective Heat Transfer," Int. J. Heat Mass Transfer, 42, pp. 3585-3597.

[65] Bejan, A., and Almogbel, M., 2000, "Constructal T-Shaped Fins," Int. J. Heat Mass Transfer, 43, pp. 2101-2115.

[66] Almogbel, M., and Bejan, A., 1999, "Conduction Trees With Spacings at the Tips,” Int. J. Heat Mass Transfer, 42, pp. 3739-3756.

[67] Vargas, J. V. C., and Bejan, A., 2002, "The Optimal Shape of the Interface Between Two Conductive Bodies With Minimal Thermal Resistance," ASME J. Heat Transfer, 124, pp. 1218-1221.

[68] Biserni, C., Rocha, L. A. O., and Bejan, A., 2004, "Inverted Fins: Geometric Optimization of the Intrusion Into a Conducting Wall," Int. J. Heat Mass Transfer, 47, pp. 2577-2586.

[69] Blyth, M. G., and Pozrikidis, C., 2003, "Heat Conduction Across Irregular and Fractal-Like Surfaces,” Int. J. Heat Mass Transfer, 46, pp. 1329-1339.

[70] Zimparov, V., 2004, "Performance Evaluation of Some Passive Augmentation Techniques Using Entropy Minimization Method," in Bejan's Constructal Theory of Shape and Structure, R. Rosa, A. H. Reis, and A. F. Miguel, eds. Évora Geophysics Centre, Évora, pp. 121-145.

[71] Zimparov, V., 2001, "Enhancement of Heat Transfer by a Combination of Three-Start Spirally Corrugated Tube With a Twisted Tape,” Int. J. Heat Mass Transfer, 44, pp. 551-574.

[72] Mereu, S., Sciubba, E., and Bejan, A., 2001, "The Optimal Cooling of a Stack of Heat Generating Boards With Fixed Pressure Drop, Flow Rate or Pumping Power," Int. J. Heat Mass Transfer, 36, pp. 3677-3686.

[73] Ogiso, K., 2001, "Assessment of Overall Cooling Performance in Thermal Design of Electronics Based on Thermodynamics," ASME J. Heat Transfer, 123, pp. 999-1005.

[74] Ghodoossi, L., and Egrican, N., 2003, "Exact Solution for Cooling of Electronics Using Constructal Theory," J. Appl. Phys., 93, pp. 4922-4929.

[75] Gosselin, L., and Bejan, A., 2004, "Constructal Thermal Optimization of an Electromagnet,” Int. J. Therm. Sci., 43, pp. 331-338.

[76] Xia, Z. Z., Li, Z. X., and Guo, Z. Y., 2003, "Heat Conduction Optimization: High Conductivity Constructs Based on the Principle of Biological Evolution," Proceedings of the 12th International Heat Transfer Conference, Grenoble, August $18-23$.

[77] da Silva, A. K., Lorente, S., and Bejan, A., 2004, "Optimal Distribution of Discrete Heat Sources on a Wall With Natural Convection,” Int. J. Heat Mass Transfer, 47, pp. 203-214.

[78] da Silva, A. K., Lorente, S., and Bejan, A., 2004, "Optimal Distribution of Discrete Heat Sources on a Plate With Laminar Forced Convection," Int. J. Heat Mass Transfer, 47, pp. 2139-2148

[79] Abu-Hijleh, B. A., 2003, "Optimized Use of Baffles for Reduced Natural Convection Heat Transfer From a Horizontal Cylinder," Int. J. Therm. Sci., 42, pp. 1061-1071.

[80] Bejan, A., 2004 "Designed Porous Media: Maximal Heat Transfer Density at Decreasing Length Scales,” Int. J. Heat Mass Transfer, 47, pp. 3073-3083.

[81] Alharbi, A. Y., and Pence, D. V., 2003, "Temperature Distributions in Microscale Fractal-Like Branching Channel Networks," Proceedings of the ASME Summer Heat Transfer Conference.

[82] Luo, L., Tondeur, D., and Gruss, A., 2003, "Intensification des Transferts et Conception des Échangeurs Multi-Échelles," Proceeding of the Congrés Français de Thermique, Genoble.

[83] Azoumah, Y., Mazet, N., and Neveu, P., 2004, "Constructal Network for Heat and Mass Transfer in a Solid-Gas Reactive Porous Medium," Int. J. Heat Mass
Transfer, 47, pp. 3313-3320

[84] Rivera-Alvarez, A., and Bejan, A., 2003, "Constructal Geometry and Operation of Adsorption Processes," Int. J. Therm. Sci., 42, pp. 983-994.

[85] Pence, D. V., 2002, "Reduced Pumping Power and Wall Temperature in Microchannel Heat Sinks With Fractal-Like Branching Channel Networks," Microscale Thermophys. Eng., 6, pp. 319-330.

[86] Lorente, S., and Bejan, A., 2002, "Combined 'Flow and Strength' Geometric Optimization: Internal Structure in a Vertical Insulating Wall With Air Cavities and Prescribed Strength," Int. J. Heat Mass Transfer, 45(16), pp. 3313-3320.

[87] Gosselin, L., Bejan, A., and Lorente, S., 2004, "Combined 'Heat Flow and Strength' Optimization of Geometry: Mechanical Structures Most Resistant to Thermal Attack," Int. J. Heat Mass Transfer, 47, pp. 3477-3489.

[88] Favre-Marinet, M., Le Person, S., and Bejan, A., 2003, "Maximum Heat Transfer Rate Density in Two-Dimensional Minichannels and Microchannels," The First International Conference on Microchannels and Minichannels Proceedings ASME, S. G. Kandlikar, ed., pp. 765-772.

[89] Bejan, A., 2002, "Dendritic Constructal Heat Exchanger With Small-Scale Crossflows and Larger-Scales Counterflows," Int. J. Heat Mass Transfer, 45(23), pp. 4607-4620

[90] Bejan, A., 2003, "Optimal Internal Structure of Volumes Cooled by SinglePhase Forced and Natural Convection," J. Electron. Packag., 125, pp. 200 207.

[91] Bejan, A., and Fautrelle, Y., 2003, "Constructal Multi-Scale Structure for Maximal Heat Transfer Density," Acta Mech., 163, pp. 39-49.

[92] Bello-Ochende, T., and Bejan, A., 2003, "Fitting the Duct to the 'Body' of the Convective Flow," Int. J. Heat Mass Transfer, 46, pp. 1693-1701.

[93] Cizmas, P. G., and Bejan, A., 2001, "Optimal Placement of Cooling Flow Tubes in a Wall Heated From the Side," Int. J. Transp. Phenom., 3(4), pp. 331-343.

[94] Nelson, R. A., Jr., and Bejan, A., 1998, "Constructal Optimization of Internal Flow Geometry in Convection,” ASME J. Heat Transfer, 120, pp. 357-364.

[95] Ledezma, G. A., Bejan, A., and Errera, M. R., 1997, "Constructal Tree Networks for Heat Transfer," J. Appl. Phys., 82(1), pp. 89-100.

[96] Neagu, M., and Bejan, A., 2001, "Constructal Placement of High-Conductivity Inserts in a Slab: Optimal Design of Roughness," ASME J. Heat Transfer, 123, pp. 1184-1189.

[97] Vargas, J. V. C., and Bejan, A., 2004, "Thermodynamic Optimization of Internal Structure in a Fuel Cell," Int. J. Energy Res., 28, pp. 319-339.

[98] Ordonez, J. C., and Bejan, A., 2003, "System-Level Optimization of the Sizes of Organs for Heat and Fluid Flow Systems," Int. J. Therm. Sci., 42, pp. $335-342$.

[99] Costa, V. A. F., 2004, "Visualisation of Heat and Mass Transfer Using Heatlines and Masslines," in Bejan's Constructal Theory of Shape and Structure, R. Rosa, A. H. Reis, and A. F. Miguel, eds., Évora Geophysics Centre, Évora, pp. $147-169$.

[100] Ordonez, J. C., and Bejan, A., 2003, "Minimum Power Requirement for Environmental Control of Aircraft," Energy, 28, pp. 1183-1202.

[101] Rosa, R., 2004, "River Basins: Geomorphology and Dynamics," in Bejan's Constructal Theory of Shape and Structure, R. Rosa, A. H. Reis, and A. F. Miguel, eds., Évora Geophysics Centre, Évora, pp. 15-47.

[102] Errera, M. R., and Bejan, A., 1998, "Deterministic Tree Networks for River Drainage Basins," Fractals, 6(3), pp. 245-261.

[103] Bejan, A., and Reis, A. H., 2005, "Thermodynamic Optimization of Global Circulation and Climate," Int. J. Energy Res., 29, pp. 303-316.

[104] Reis, A. H., and Bejan, A., 2006, "Constructal Theory of Global Circulation and Climate," Int. J. Heat Mass Transfer, 49, pp. 1857-1875.

[105] Bejan, A., Ikegami, Y., and Ledezma, G. A., 1998, "Constructal Theory of Natural Crack Pattern Formation for Fastest Cooling," Int. J. Heat Mass Transfer, 41, pp. 1945-1954.

[106] Bisio, G., and Rubatto, G., 2002, "Analysis of Natural Crack Pattern Formation by Constructal Theory and Extensions to Several Nature Fields," Int. J Energy Environment Economics, 10(1), pp. 69-84.

[107] Miguel, A. F., 2004, "Constructal Analysis of Dendritic Growth," in Bejan's Constructal Theory of Shape and Structure, R. Rosa, A. H. Reis, and A. F. Miguel, eds., Évora Geophysics Centre, Èvora, pp. 75-93.

[108] Bejan, A., 2002, "Constructal Theory of Organization in Nature: Dendritic Flows, Allometric Laws and Flight," Design and Nature, C. A. Brebbia, L. Sucharov, and P. Pascolo, eds., WIT Press, Southampton, UK, pp. 57-66.

[109] Reis, A. H., Miguel, A. F., and Aydin, M., 2004, "Constructal Theory of Flow Architectures of the Lungs," Med. Phys., 31(5), pp. 1135-1140.

[110] Bejan, A., 1996, "Street Network Theory of Organization in Nature," J. Adv. Transp., 30(2), pp. 85-107.

[111] Hernandez, G., Allen, J. K., and Mistree, F., 2002, "Design of Hierarchic Platforms for Customizable Products," Proceedings of ASME 2002 Design Engineering Tech. Conference, Montreal.

[112] Feynman, R. P., Leighton, R. B., and Sands, M., 1997, "The Feynman Lectures on Physics," 6th ed., Vol. II, Chap. 19, Wiley.

[113] Callen, H. B., 1985, Thermodynamics and an Introduction to Thermostatistics, 2nd ed., Wiley, New York.

[114] Dincer, I., 2004, "Entropy Generation for the Next Generation," in Bejan's Constructal Theory of Shape and Structure, R. Rosa, A. H. Reis, and A. F. Miguel, eds., Évora Geophysics Centre, Évora, pp. 192-219.

[115] Pramanick, A. K., and Das, P. K., 2005, "Note on Constructal Theory of Organization in Nature," Int. J. Heat Mass Transfer, 48, pp. 1974-1981.

[116] Upham, G., and Wolo, J., 2004, "Coordination of Dynamic Rehabilitation Experiments of People Living With Post-Polio Syndrome and Call for Research Into PPS as a Forgotten Disease," Global Forum for Health Research, 
Mexico, November, http://www.globalforumhealth.org/forum8/forum8cdrom/Posters/Upham\%20G\%20F8-203.doc

[117] Rosa, R., 2004, Bejan's Constructal Theory of Shape and Structure, R. Rosa, A. H. Reis, and A. F. Miguel, eds., Évora Geophysics Centre, Évora, pp. $15-47$.

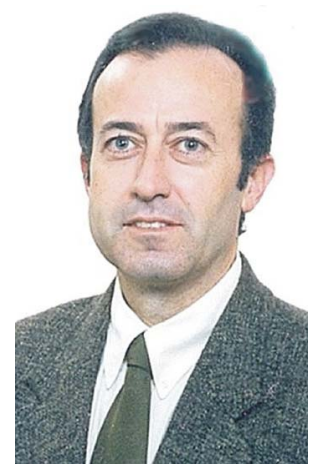

Antonio Heitor Reis was born in 1953 in S. José das Matas (Portugal), graduated in Physics at the University of Lisbon, received his M.S. in Mechanical Engineering from the Technical University of Lisbon (I.S.T.) and his Ph.D. in Physics from the University of Evora. From 1981 until 1986, he did research on energy related topics at the National Laboratory for Engineering and Technology in Lisbon. In 1986, he joined the Physics Department of the University of Évora where he holds the position of associate professor and teaches physics and engineering topics. His current research interests are atmospheric physics, flows in porous media (animate and inanimate) and Constructal Theory. 